\title{
Latitudinal Structure of Solitons in the South China Sea
}

\author{
STEVEN R. RAMP \\ Soliton Ocean Services LLC, Falmouth, Massachusetts \\ J.-H. PARK \\ Inha University, Incheon, South Korea \\ YIING JANG YANG \\ Institute of Ocean Sciences, National Taiwan University, Taipei, Taiwan \\ FREDERICK L. BAHR \\ Monterey Bay Aquarium Research Institute, Moss Landing, California \\ CHANHYUNG JEON \\ Inha University, Incheon, South Korea
}

(Manuscript received 5 April 2018, in final form 25 March 2019)

\begin{abstract}
Four current-meter moorings and 12 pressure sensor-equipped inverted echo sounders (PIES) were deployed during summer 2011 in the South China Sea. The goal of the experiment was to obtain synoptic observations of the large-amplitude nonlinear internal waves from the near field to the far field as they propagated west-northwest across the sea. The program was unique because it was the first to observe the latitudinal variability of the wave crests in addition to the transformations along a single east-west transect. The waves were strongest down the center of the PIES array along roughly $20^{\circ} 45^{\prime} \mathrm{N}$ and were weaker off axis in both directions. Both a-waves and b-waves arrived earlier in the south than the north, but with different lag times indicating different propagation directions and therefore different sources. The waves were classified by their arrival patterns and source locations and not by their amplitude or packet structure. The Stanford Unstructured Nonhydrostatic Terrain-Following Adaptive Navier-Stokes Simulator (SUNTANS) model, calibrated against the array, showed that the a-waves developed out of the internal tide spawned in the southern portion of the Luzon Strait and the b-waves originated in the north. The northern tides were refracted and suffered large dissipative losses over the shallow portion of the western ridge, whereas the southern tides propagated west-northwest unimpeded, which resulted in a-waves that were larger and appeared sooner than the b-waves. The results were consistent with previous observations that can now be understood in light of the full three-dimensional structure of the internal waves and tides in the northeastern South China Sea.
\end{abstract}

\section{Introduction}

The world's largest and most energetic nonlinear internal waves (NLIWs) have now been studied for many years transiting from their generation sites in the Luzon Strait to the Chinese continental slope northeast of Dongsha Island (Farmer et al. 2011; Alford et al. 2015). The waves are generated by the flux of the barotropic

Corresponding author: Steven R. Ramp, sramp@solitonocean.com tide across the two ridges in the strait, which are in near resonance with the semidiurnal tide (Buijsman et al. 2010a,b; Zhang et al. 2011; Alford et al. 2011). After traversing the western (Heng-Chun) Ridge, the internal tide steepens nonlinearly as it propagates WNW until it "breaks" and spawns the NLIWs (Farmer et al. 2009; Ramp et al. 2010; Alford et al. 2010; Li and Farmer 2011). Two types of mode-1 depression waves emerge to the west, the a-waves with a distinct rank-ordered packet structure and the usually solitary b-waves (Ramp et al. 2004; 
Duda et al. 2004; Alford et al. 2010). The nonlinear steepening distance/time is shorter for the a-waves, which are well developed by $118^{\circ} 30^{\prime} \mathrm{E}$ near the $2000-\mathrm{m}$ isobath. The b-waves appear later and farther west, but are easily observed as NLIW in water depths of $500 \mathrm{~m}$ or less (Ramp et al. 2018, manuscript submitted to Nonlinear Processes Geophys.). Both wave types create regions of surface convergence (roughness) and divergence (smoothness) along the crests that are visible for hundreds of kilometers by eye, ship's radar, and spaceborne sensors (Liu et al. 2004; Jackson 2009). The waves transform dramatically upon shoaling via dispersion, breaking, and the formation of trapped cores (Vlasenko and Hutter 2002; Ramp et al. 2004; Lien et al. 2005, 2012; Vlasenko and Stashchuk 2007; Lamb and Warn-Varnas 2015; Ramp et al. 2018, manuscript submitted to Nonlinear Processes Geophys.). Over the continental shelf when the upper-layer thickness exceeds the lower-layer thickness, usually less than 120-m depth, the waves transform into elevation waves (Orr and Mignerey 2003; Ramp et al. 2004). The waves then continue to propagate shoreward and presumably dissipate in shallow water although observations there are sparse.

To date, most of the observational work cited above has been focused along a single two-dimensional transect roughly along $20^{\circ} 30^{\prime} \mathrm{N}$ extending from a point between Batan and Itbayat Island in the Batanes Province, Philippines, to the former Asian Seas International Acoustics Experiment (ASIAEX) site northwest of Dongsha reef. These studies have effectively characterized the amplitudes, propagation speeds, orbital velocities, and arrival patterns in the waves. The speeds range from $3.3 \mathrm{~m} \mathrm{~s}^{-1}$ in the deep basin, decreasing to $2.2 \mathrm{~m} \mathrm{~s}^{-1}$ over the continental slope, to $1.6 \mathrm{~m} \mathrm{~s}^{-1}$ over the upper slope (Alford et al. 2010; Ramp et al. 2010, 2018, manuscript submitted to Nonlinear Processes Geophys.; Li and Farmer 2011). These speeds are typically $5 \%$ faster than the linear mode1 wave speed due to large-amplitude nonlinearity (Alford et al. 2010). The orbital velocities are in the same direction as wave propagation in the upper layer and the opposite in the lower layer, with a nodal point near 120-m depth (Ramp et al. 2004; Duda et al. 2004). The waves arrive in groups or "clusters" centered plus or minus 4 days about the fortnightly spring tide. Thus, there are $3-4$ days between each fortnightly cycle on which no waves form at all (Ramp et al. 2010). It has been suggested that this is due to some critical amplitude (Vlasenko et al. 2012) or velocity (Ramp et al. 2010) that is necessary over the east (Lan $\mathrm{Yu}$ ) Ridge in the Luzon Strait in order for the nonlinear waves to form. There also seem to be fewer waves observed in winter (Kao et al. 2007; Ramp et al. 2010). This may be due to changes in stratification and the surface mixed layer depth (Shaw et al. 2009) but may also be because the waves were missed observationally due to refraction by the Kuroshio (Park and Farmer 2013).

Much attention has been focused in the literature on the dynamical distinction between the a-waves and the b-waves. Observationally, the a-wave arrivals tend to track the diurnal tide and the b-waves the semidiurnal. The consensus opinion today, however, is that both waves are generated primarily by the semidiurnal tide as modulated by the diurnal tide, due to much greater rotational dispersion acting on the diurnal tide (Helfrich and Melville 2006; Helfrich 2007; Farmer et al. 2009; Vlasenko et al. 2012). By tracing the wave phase back to the source, Alford et al. (2010) and Ramp et al. (2010) concluded that a-waves were generated as lee waves on the ebb tide in the Luzon Strait and were released when the tide turned (the "release" mechanism) (Buijsman et al. 2010a; Vlasenko et al. 2012), whereas b-waves were generated on the flood tide (the "onset" or "evolutionary" mechanism) (Buijsman et al. 2010a; Vlasenko et al. 2012). In a more recent experiment over the continental slope just north of the ASIAEX site, the wave-arrival patterns were once again a rigorous match with the generating tide at Luzon with the a-waves correlating with the ebb tide and the b-waves with the flood (Ramp et al. 2018, manuscript submitted to Nonlinear Processes Geophys.). They also found insufficient energy in the two weaker tidal beats to generate NLIWs. Using several datasets and the MITgcm numerical model, (Vlasenko et al. 2012) came down in favor of both waves being generated on alternate beats of the flood tide, with the stronger beat forming a-waves and the weaker beat b-waves, claiming insufficient tidal excursion to form lee waves. It has now been demonstrated unequivocally, however, that lee waves do form over the East Ridge in the Luzon Strait (Pinkel et al. 2012). There is furthermore the possibility that the a-waves and b-waves are generated at different locations in the Strait, possibly several. Using satellite remote sensing observations and the Dietrich/Center for AirSea Technology (DieCAST) model, Du et al. (2008) suggested two possible generation sites, one near Batan and one near Babuyan, but did not connect a particular wave type with a specific generation site. Based on a fully three-dimensional, fully nonlinear numerical model (Zhang et al. 2011) suggested that the bottom topography near Batan Island is conducive to semidiurnal internal tide formation while farther south near the Babuyan Strait the bottom slope favors the diurnal tide. Via beam-tracing they show the a-waves propagating slightly more northward than the b-waves, a result also evident in the observations (Ramp et al. 2010). Averaged over an entire year, they showed the a-waves traveling WNW toward $288^{\circ} \mathrm{N}$ and the b-waves traveling 
toward $282^{\circ} \mathrm{N}$ (Ramp et al. 2010). Using output from the Luzon Strait Ocean Nowcast/Forecast System (LZSNFS), Chen et al. (2013) found that both types of waves were generated by the ebb tide in the Luzon Strait, with the a-waves forming at the East Ridge and the b-waves at the West Ridge.

To more definitively identify the wave generation mechanisms and locations, the Internal Waves in Straits Experiment (IWISE) was launched in 2009. The experiment featured a much denser array of observational assets at the supposed sources and in the near field, but also included off-axis observations in the far field to confirm the associated wave-arrival patterns. The three datasets assembled here were collected during 2011 and include the near-field moorings sensing velocity components $u$ and $v$, temperature $T$, and salinity $S$; an array of pressure sensor-equipped inverted echo sounders (PIES), and two moorings in the deep basin, also observing $u, v, T$, and $S$. The observational details are presented in section 2 , followed by a description of the far-field wave-arrival patterns in the deep basin in section 3. In section 4, the waves are traced back through the PIES array to determine their geographical source. The observational results are compared with output from the Stanford Unstructured Nonhydrostatic Terrain-Following Adaptive Navier-Stokes Simulator (SUNTANS) three-dimensional numerical model in section 5 , and the results are summarized in section 6 .

\section{Data and methods}

The basin moorings north $(\mathrm{N})$ and south $(\mathrm{S})$, as they will be called hereinafter, were deployed from 5 July to 6 September 2011 on the 1584- and 2584-m isobaths, respectively, at $20^{\circ} 14.7^{\prime} \mathrm{N}$ and $21^{\circ} 28.3^{\prime} \mathrm{N}$ along $118^{\circ} 03.7^{\prime} \mathrm{E}$ (Fig. 1). Both moorings spanned the entire water column with $T$ and $S$ sensors and had an upward-looking $75-\mathrm{kHz}$ ADCP at nominally 500-m depth. The $T$ and $S$ sensors were separated by $60 \mathrm{~m}$ from 10 to $500 \mathrm{~m}$ on both moorings. Below $500 \mathrm{~m}$, these sensors were located at $520,1030,1285$, and $1540 \mathrm{~m}$ on mooring $\mathrm{N}$ and 730,930 , 1540,2050 , and $2560 \mathrm{~m}$ on mooring S. The $T$ and $S$ were sampled at 1-min intervals: the velocity was sampled once per second in 16-m bins and averaged to 60-s intervals. Mooring blow-down was small at mooring $\mathrm{N}$ but was substantial at the longer mooring $\mathrm{S}$, especially when the local currents due to tides and mesoscale eddies were in the same direction. The mooring was intermittently pushed down as much as $200 \mathrm{~m}$ at these times. To cope with this fact, the data were mapped to a standard grid and the grid was then subsampled for further analysis.

The $3 \times 4$ PIES array spanned $20^{\circ} 00^{\prime}-21^{\circ} 30^{\prime} \mathrm{N}$ and $118^{\circ} 48^{\prime}-121^{\circ} 30^{\prime} \mathrm{E}$ with approximately even spacing. Two

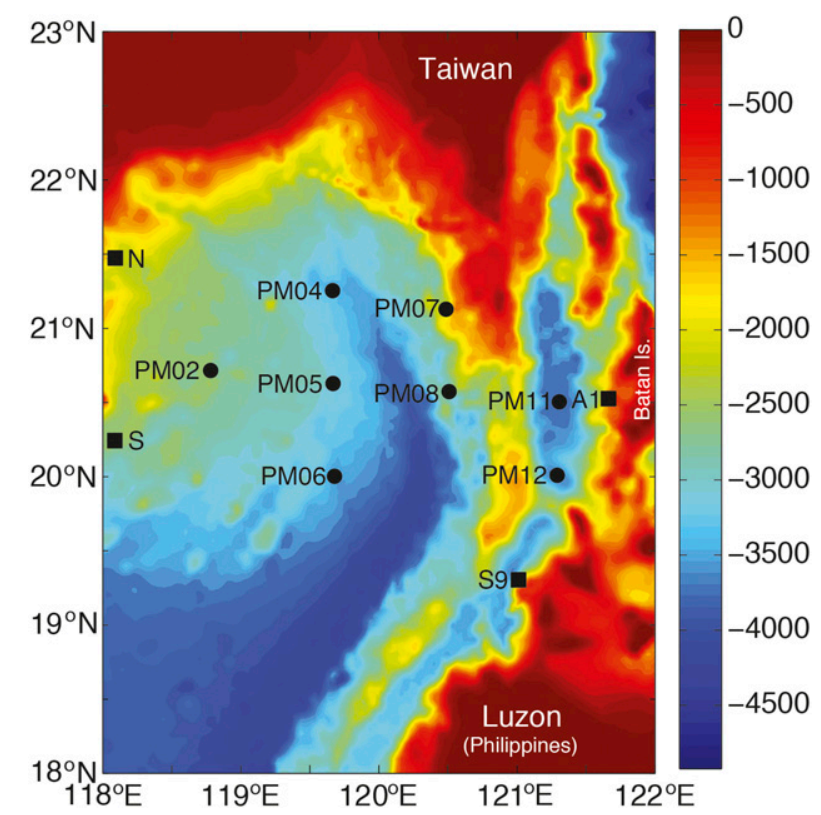

FIG. 1. Plan view of the IWISE 2011 observational assets. Moorings are indicated by the black squares, and PIES are shown by the black dots. The bottom depth is indicated by the color bar.

instruments failed (09 and 10), and two were not set up to sample internal waves (01 and 03$)$. The remaining eight instruments used in this study worked well from July to December 2011 (Fig. 1). The PIES measures the acoustic travel time of a $12-\mathrm{kHz}$ ping to the surface and back using an instrument fixed to the bottom. Nonlinear internal waves are clearly observed by the instrument because of their very large perturbations of the thermocline, which in turn alter the travel time. Travel times were converted to thermocline displacements at the rate of $1 \mathrm{~ms}$ of acoustic echo time $=24 \mathrm{~m}$ of change in thermocline depth. The veracity of the method in the South China Sea has been demonstrated by direct comparison with oceanographic moorings ( $\mathrm{Li}$ et al. 2009). The acoustic travel times were measured every 6 or $10 \mathrm{~s}$ and filtered into 2-min samples and thus provide outstanding temporal resolution of the passing internal waves.

The source moorings A1 and S9 were located on the eastern ridge in the central and southern Luzon Strait respectively, from 8 June to 8 August 2011 (Pickering et al. 2015). At mooring A1 $\left(20^{\circ} 31.4^{\prime} \mathrm{N}, 121^{\circ} 40.5^{\prime} \mathrm{E}\right.$, $1446 \mathrm{~m}$ ) a "Stablemoor" platform at a depth of $705 \mathrm{~m}$ housed upward- and downward-looking $75-\mathrm{kHz}$ acoustic Doppler current profilers (ADCPs), which measured velocity over depths of $120-650$ and $725-1200 \mathrm{~m}$ with 5-min time resolution. An upward-looking $300-\mathrm{kHz}$ $\mathrm{ADCP}$ at $80 \mathrm{~m}$ measured near-surface velocity. Temperature and salinity sensors were deployed along the mooring with 2-min sampling rates. At mooring S9 
TABLE 1. The positions, bottom depths, and start/stop times for the observational assets used in this study.

\begin{tabular}{|c|c|c|c|c|c|c|c|}
\hline Name & Type & Lat $(\mathrm{N})$ & Lon $(\mathrm{E})$ & Bottom depth (m) & Start & Stop & Comment \\
\hline $\mathrm{N}$ & Mooring & $21^{\circ} 28.3^{\prime}$ & $118^{\circ} 03.7^{\prime}$ & 1584 & 5 Jul 2011 & 6 Sep 2011 & ADCPs and $T$ and $S$ \\
\hline$S$ & Mooring & $20^{\circ} 14.7^{\prime}$ & $118^{\circ} 03.7^{\prime}$ & 2584 & 5 Jul 2011 & 6 Sep 2011 & ADCPs and $T$ and $S$ \\
\hline PM01 & PIES & $21^{\circ} 23.4^{\prime}$ & $118^{\circ} 43.2^{\prime}$ & 1898 & 4 Jul 2011 & 6 Apr 2012 & Slower sampling; not used \\
\hline PM02 & PIES & $20^{\circ} 42.6^{\prime}$ & $118^{\circ} 46.2^{\prime}$ & 2682 & 4 Jul 2011 & 31 Dec 2011 & \\
\hline PM03 & PIES & $20^{\circ} 01.0^{\prime}$ & $118^{\circ} 48.6^{\prime}$ & 2318 & 2 Jul 2011 & 6 Apr 2012 & Slower sampling; not used \\
\hline PM04 & PIES & $20^{\circ} 15.6^{\prime}$ & $119^{\circ} 40.2^{\prime}$ & 3442 & 1 Jul 2011 & 12 Dec 2011 & \\
\hline PM05 & PIES & $20^{\circ} 37.2^{\prime}$ & $119^{\circ} 40.2^{\prime}$ & 3150 & 2 Jul 2011 & 2 Dec 2011 & \\
\hline PM06 & PIES & $20^{\circ} 00.0^{\prime}$ & $119^{\circ} 40.2^{\prime}$ & 3546 & 2 Jul 2011 & 18 Dec 2011 & \\
\hline PM07 & PIES & $21^{\circ} 07.8^{\prime}$ & $120^{\circ} 30.0^{\prime}$ & 2134 & 19 Jun 2011 & 31 Dec 2011 & \\
\hline PM08 & PIES & $20^{\circ} 34.2^{\prime}$ & $120^{\circ} 30.0^{\prime}$ & 2425 & 14 Jun 2011 & 31 Dec 2011 & \\
\hline PM09 & PIES & $20^{\circ} 00.0^{\prime}$ & $120^{\circ} 30.0^{\prime}$ & & 14 Jun 2011 & - & Not recovered \\
\hline PM10 & PIES & $21^{\circ} 00.0^{\prime}$ & $121^{\circ} 18.0^{\prime}$ & 3692 & 19 Jun 2011 & 11 Apr 2012 & Bad data \\
\hline PM11 & PIES & $20^{\circ} 30.0^{\prime}$ & $121^{\circ} 18.0^{\prime}$ & 3720 & 17 Jun 2011 & 31 Dec 2011 & \\
\hline PM12 & PIES & $20^{\circ} 00.0^{\prime}$ & $121^{\circ} 18.0^{\prime}$ & 3704 & 17 Jun 2011 & 31 Dec 2011 & \\
\hline A1 & Mooring & $20^{\circ} 31.4^{\prime}$ & $121^{\circ} 40.5^{\prime}$ & 1446 & 8 Jun 2011 & 8 Aug 2011 & ADCPs and $T$ and $S$ \\
\hline S9 & Mooring & $19^{\circ} 18.0^{\prime}$ & $121^{\circ} 01.1^{\prime}$ & 2286 & 8 Jun 2011 & 8 Aug 2011 & McLane profilers, ADCPs, and $T$ and $S$ \\
\hline
\end{tabular}

$\left(19^{\circ} 18^{\prime} \mathrm{N}, 121^{\circ} 1.8^{\prime} \mathrm{E}, 2286 \mathrm{~m}\right)$ two McLane Research Laboratories, Inc., moored profilers (MPs) profiled depth ranges of 330-1260 and 1300-2220 m, measuring horizontal velocity, temperature, and salinity. The MP profiled at a nominal speed of $0.25 \mathrm{~m} \mathrm{~s}^{-1}$ and produced a complete profile approximately every hour. The resulting vertical resolution was $10 \mathrm{~m}$ for velocity and $2 \mathrm{~m}$ for density. A subsurface float at $300 \mathrm{~m}$ contained an upwardlooking $75-\mathrm{kHz}$ ADCP that measured velocity from 30 to $300 \mathrm{~m}$. Between this float and a smaller float at $70 \mathrm{~m}$, a T-chain with sensors spaced $15 \mathrm{~m}$ apart measured temperature. Salinity was estimated from the $T$ chain using the observed $T-S$ relation. To correct for mooring blow-down by the strong currents, the data from both moorings were interpolated onto a uniform grid with $10-\mathrm{m}$ vertical and 1.5-h temporal spacing (Pickering et al. 2015). The locations and start and stop times for all of the assets illustrated in Fig. 1 are summarized in Table 1.

\section{Results}

\section{a. Wave-arrival patterns at moorings $N$ and $S$}

The bandpass-filtered temperature data provide an overview of oceanographic conditions during the experiment (Fig. 2). The moored array captured five fortnights or "clusters" of wave activity surrounding new moons on 1 July, 30 July, and 29 August and full moons on 15 July and 13 August. The fortnightly beat was more distinct at mooring $\mathrm{S}$ than at mooring $\mathrm{N}$, and the tides near spring tide were almost purely diurnal (Figs. 2b,e). The wave-arrival patterns, indicated by spikes in the high-pass-filtered time series (Figs. 2c,f) were generally similar for each cluster but differed in the details because of varying oceanographic conditions along the propagation path. Between each cluster there were periods ranging from 4 to 7 days during which no waves were observed at the moorings corresponding to the times surrounding the neap tide in the Luzon Strait. Arrival patterns lag the lunar cycle somewhat due to the travel time from the presumed generation sites located to the east in the Luzon Strait. This issue is examined in greater detail subsequently. Note that not all fortnights were the same: In particular, both the internal tide and the resulting internal wave field were weaker during cluster 4 . This may be due to mesoscale effects that shift the interference patterns near the supposed sources in the Luzon Strait (Park and Farmer 2013; Pickering et al. 2015; Li et al. 2016).

Many features of the wave-arrival patterns can be ascertained from the stack plots of ocean temperature over the upper $500 \mathrm{~m}$ from moorings $\mathrm{N}$ and $\mathrm{S}$ (Figs. 3-5). The a-waves and b-waves will be referred to here as "families" of waves that can be identified unambiguously by their arrival patterns and arrival times, irrespective of the number of waves per packet. While it is generally true that b-waves are solitary and a-waves form packets, this was not always the case during this experiment. It shall be demonstrated subsequently that the wave amplitudes and orbital velocities of the a-waves and b-waves overlapped: Some large b-waves formed packets, and the smaller a-waves were solitary. The criterion of packets versus solitary waves alone is therefore not a valid method to identify a-waves and b-waves. The key to understanding the differences in these families of waves lies in identifying their generating location and mechanism.

One representative example from 13 to 22 July (cluster 2) shows many of the key features (Fig. 3). The a-waves at mooring $\mathrm{N}$ began arriving two days before the b-waves and continued one day after, and in this case were also larger and formed packets. Note that the 

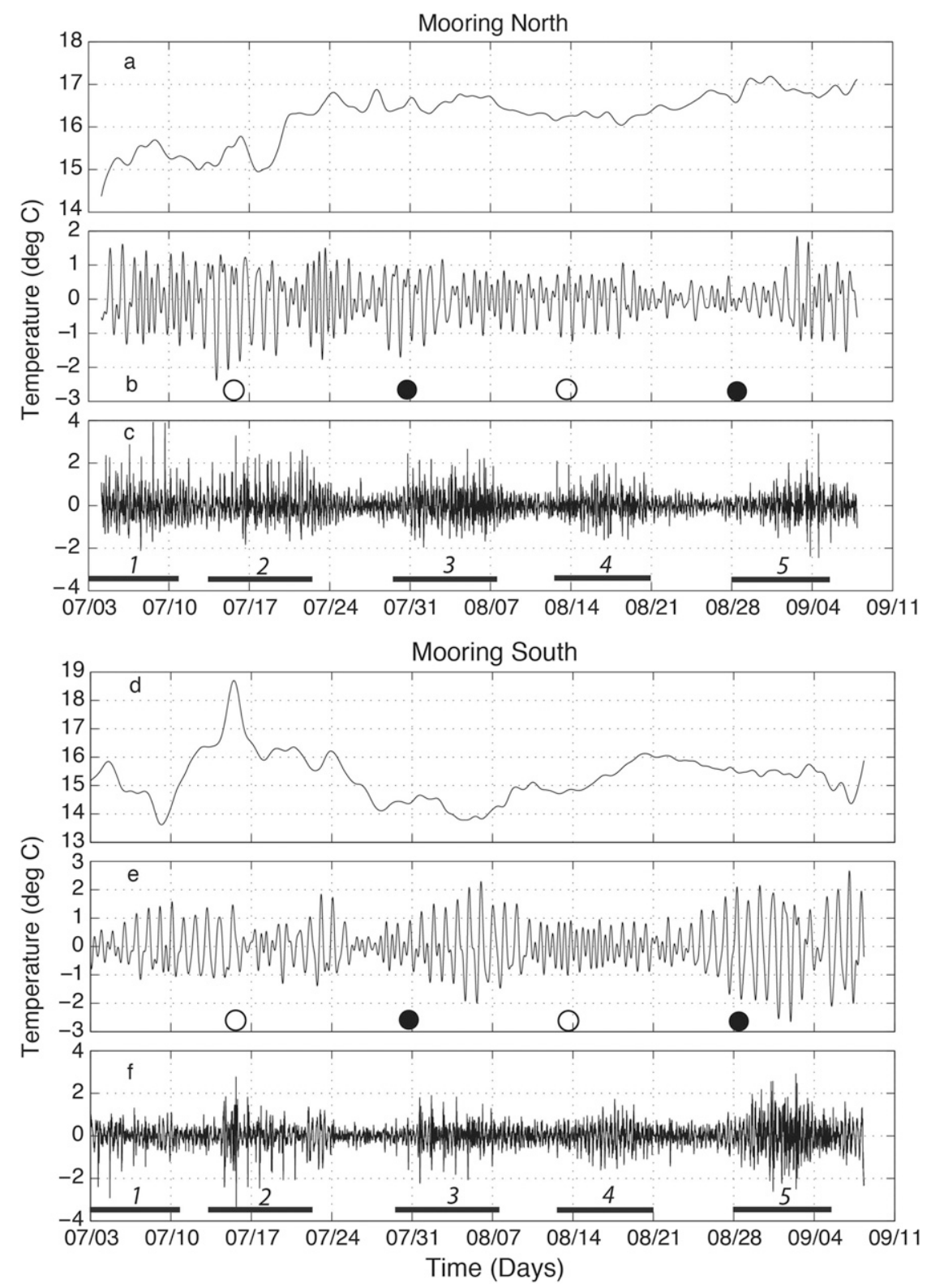

FIG. 2. Bandpass-filtered temperature data from 195-m depth at mooring $\mathrm{N}$ and from $190-\mathrm{m}$ depth at mooring S. The thermal displacements at this depth captured the passing NLIWs and internal tides. Shown are the subtidal, tidal, and high-frequency time series for (a)-(c) mooring $\mathrm{N}$ and (d)-(f) mooring $\mathrm{S}$. The temperature scale is absolute for the subtidal data and represents anomalies from the mean for the tidal and high-frequency plots. Phases of the moon are indicated by filled (new moon) and open (full moon) circles, respectively. The numbers $1-5$ across the bottom identify clusters of arriving nonlinear internal waves as described in the text. Clusters 2, 4, and 5 are shown later in more detail in Figs. 3, 4, and 5, respectively.

a-waves did not arrive exactly $24 \mathrm{~h}$ apart as in previous experiments (Ramp et al. 2004, 2010). This resulted from differences in the barotropic tide in the Luzon Strait, which is very complicated and varies from year to year. The b-wave arrivals on 16-18 July led the a-waves by $8 \mathrm{~h} 20 \mathrm{~min}$. The b-waves arrived toward the second half of the fortnightly envelope, and that was typical of all fortnights observed. The b-waves arrived about an hour later each day, similar to the semidiurnal tide, also as observed in previous experiments. At mooring $\mathrm{S}$, the a-wave-arrival patterns were similar to mooring $\mathrm{N}$ but arrived on average $4 \mathrm{~h} 15 \mathrm{~min}$ earlier (Fig. 3). There were 

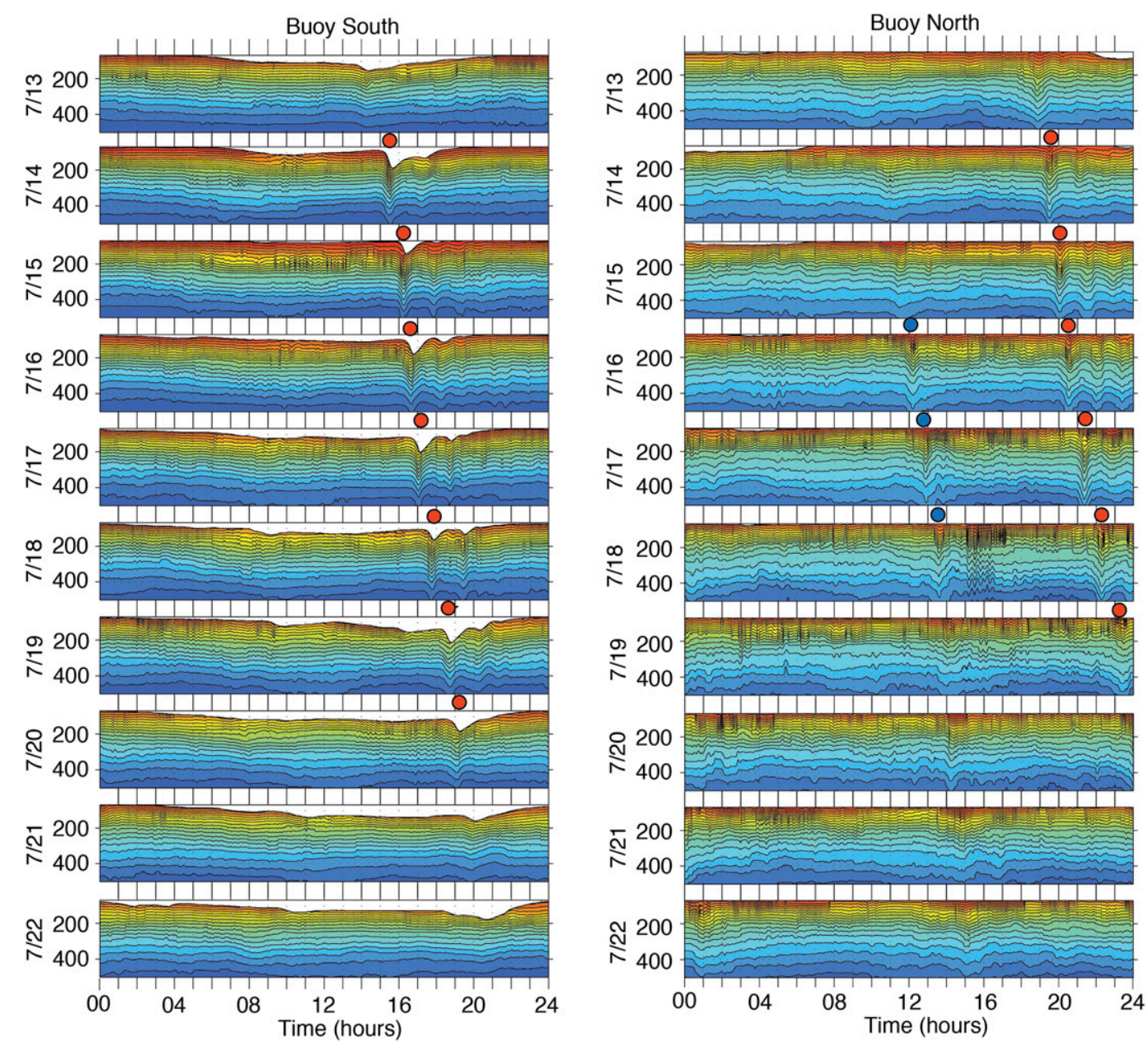

FIG. 3. Temperature contours for the two moorings from 13 to $22 \mathrm{Jul} 2011$ for cluster 2. Each panel represents one day, with hourly ticks across the bottom. The a-wave and b-wave arrivals are indicated by red and blue dots, respectively. White areas near the surface at mooring $\mathrm{S}$ are due to mooring blow-down; the blow-down was more severe at mooring $\mathrm{S}$, which was $1000 \mathrm{~m}$ taller than mooring $\mathrm{N}$.

at least two and possibly three waves per packet. No b-waves were observed at all for mooring $\mathrm{S}$ cluster 2. This implies that the southward extent of the a-waves was greater than the $b$-waves during this time.

Another case shows a time when the b-waves were prominent at both moorings but the a-waves were weak at buoy S (Fig. 4). This time spanning 12-21 August is the second half of cluster 4 following the full moon on 13 August. The a-wave arrivals at mooring $\mathrm{N}$ were strong starting at 1900 UTC 12 August, again arriving about an hour later each day. Starting on 17 August, the b-wave arrivals began and the a-waves trailed the $\mathrm{b}$-waves by about $10 \mathrm{~h}$. At mooring $\mathrm{S}$ the $\mathrm{b}$-waves were weaker but still discernable. Only two a-waves appeared at buoy $\mathrm{S}$ on 14-15 August. For these a-waves, mooring $\mathrm{S}$ led mooring $\mathrm{N}$ by on average $3 \mathrm{~h} 45 \mathrm{~min}$, about onehalf hour less than for cluster 2 .
A third case is presented for 28 August to 6 September (Fig. 5, cluster 5), whence the usually much stronger and more prevalent a-waves were not observed at either mooring. The b-waves were quite strong during this time, as strong as the a-waves in other clusters. Several exhibited a clear packet structure, as for instance 1-3 September at mooring S and 3-4 September at mooring $\mathrm{N}$. At the time when the a-waves appeared during other clusters, around 1930 UTC at mooring S and 2130 UTC for mooring N, an energetic field of ordinary internal waves appeared instead. This was especially clear on 31 August and 1 September at mooring S and 2-5 September at mooring N.

\section{b. Differences between moorings}

The wave arrival times between the two moorings are now discussed in more detail. The a-waves at mooring $\mathrm{S}$ 

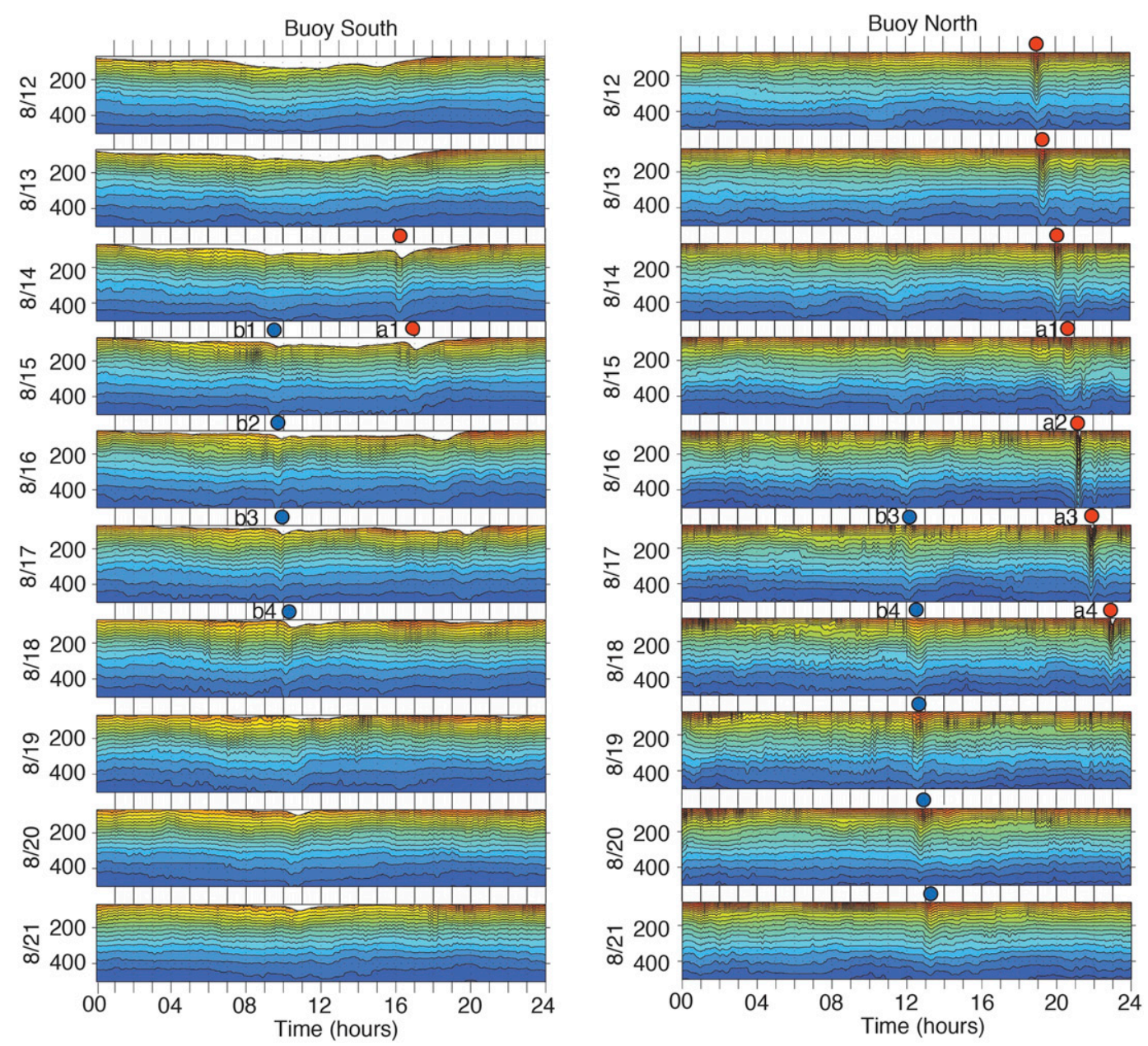

FIG. 4. As in Fig. 3, but for cluster 4 from 12 to 21 Aug 2011. The lowercase letters a and b indicate the same waves that are annotated in the SUNTANS model output (Fig. 15, below).

for cluster 2 arrived on average about $4 \mathrm{~h} 20$ min earlier than the a-waves at mooring $\mathrm{N}$. This compared to $3 \mathrm{~h}$ $33 \mathrm{~min}$ for cluster 3 and $3 \mathrm{~h} 46 \mathrm{~min}$ for cluster 4 , but the waves always arrived first at mooring $\mathrm{S}$. This was true for the less frequent $b$-waves as well, although the average time lag for the $\mathrm{b}$-waves between moorings $\mathrm{S}$ and $\mathrm{N}$ was only $2 \mathrm{~h} 20 \mathrm{~min}$. These results can be understood by considering the shape and propagation direction of the wave crests as seen for instance in the satellite image from 5 August 2011 (Fig. 6). The a-wave crests visible in the image clearly passed by the southern mooring first. While both the image and the moored time series show that there were no b-waves on this day, it can be deduced that the slightly more westward propagation direction of the bwaves would reduce the arrival-time difference between moorings. The satellite image also allows computation of the wave propagation speeds by comparing the image with the time of wave passage at the two moorings. The difference, $2.58 \mathrm{~m} \mathrm{~s}^{-1}$ at mooring $\mathrm{N}$ and $3.33 \mathrm{~m} \mathrm{~s}^{-1}$ at mooring
$\mathrm{S}$, can be accounted for primarily by the difference in the water depth (2584 vs $1584 \mathrm{~m}$ ) at the two locations.

The propagation directions and wave orbital velocities can be further quantified using the moored velocity data. The method assumes the theoretical result that the mode- 1 depression waves were propagating in the same direction as the upper-layer velocity, which has proven accurate in several previous experiments and is a close match to the satellite imagery (Ramp et al. 2004, 2010). The histograms of speed and direction (Fig. 7) show that on average the a-waves were stronger than the b-waves and propagated more toward the northwest. The mean speeds at buoy $\mathrm{N}$ were 34.8 and $28.0 \mathrm{~cm} \mathrm{~s}^{-1}$ for the a- and b-waves, respectively. The a-waves were headed on average toward $312^{\circ}$ versus $300^{\circ}$ for the b-waves, a difference of $12^{\circ}$. At buoy $\mathrm{S}$, the mean speeds were 23.1 and $22.6 \mathrm{~cm} \mathrm{~s}^{-1}$ for the a-waves and b-waves, respectively, in the direction of $283^{\circ} / 262^{\circ}$. On average, the histograms confirm the result that the propagation direction of the 

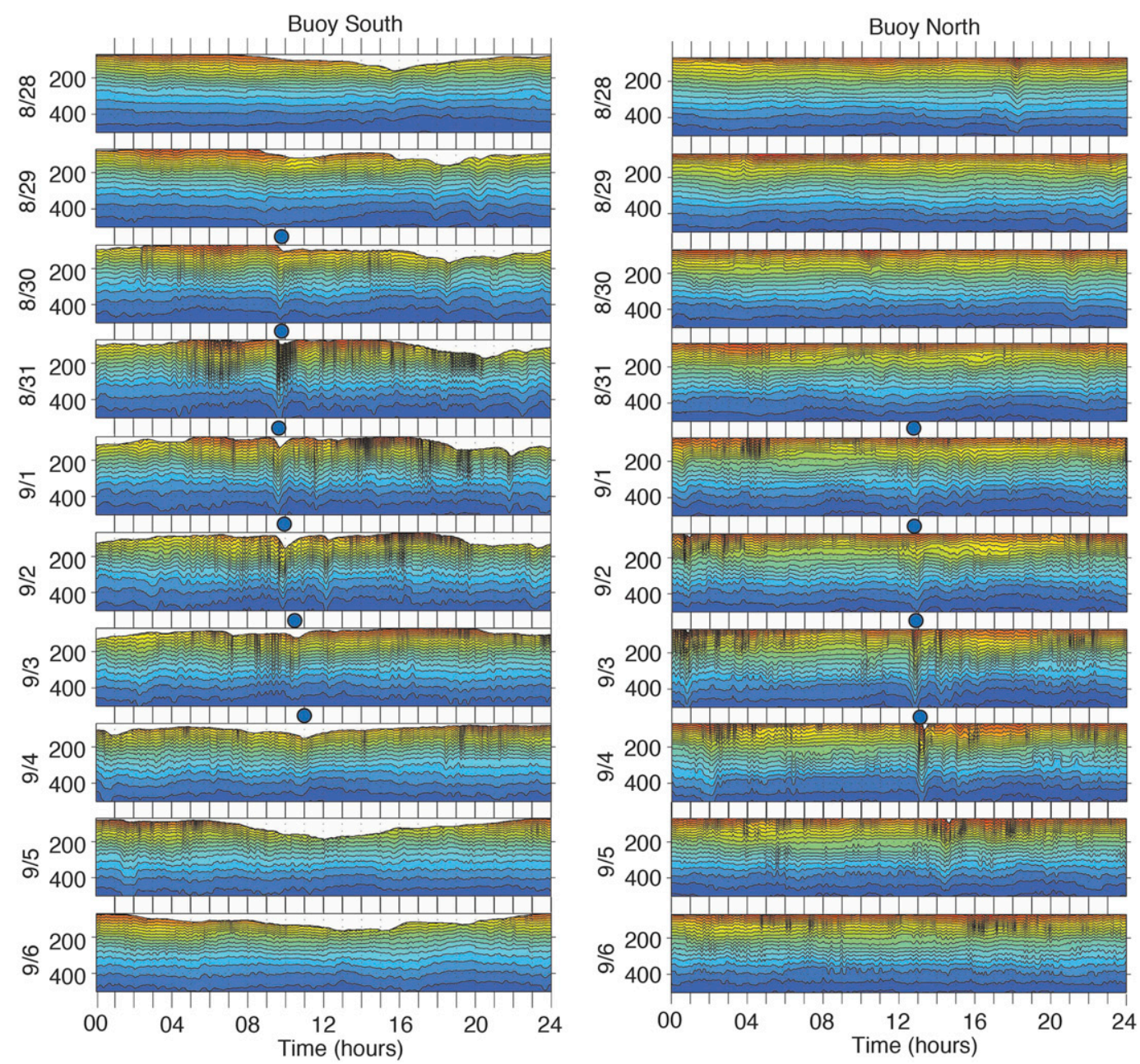

FIG. 5. As in Fig. 3, but for cluster 5 from 28 Aug to 6 Sep 2011. The a-waves were absent during this time.

a-waves was $11^{\circ}-12^{\circ}$ to the north of the b-waves. This change in the orientation of the wave crest can account for the shorter lag time between moorings for the b-waves versus the a-waves. The larger scatter in the directions at mooring $\mathrm{S}$ was perhaps due to its location closer to the edge of the wave crests where the curvature was greater (Fig. 6). The curvature of the wave crests also accounts for the more southerly propagation direction of both types of waves at mooring $\mathrm{S}$ than at mooring $\mathrm{N}$. The wave orbital velocities were much less than the propagation speeds at both locations, consistent with earlier experiments in deep water (Ramp et al. 2010). The waves were freely propagating in this region without breaking or forming trapped cores. This contrasts with observations over the upper continental slope, where the two speeds gradually approach each other and breaking occurs (Lien et al. 2012, 2014; Ramp et al. 2004, 2010).

The anatomy of a few individual waves is now explored further using expanded-scale plots of temperature and velocity for 16 July and 4 September 2011 (Figs. 8, 9). The 16 July data featured a clear a-wave with three waves in the packet at both moorings, and also a solitary b-wave at mooring $\mathrm{N}$ only. The a-waves were mode- 1 depression waves at both sites with the nodal point (zero velocity crossing) between 200 and $250 \mathrm{~m}$. The b-wave structure was less obvious, with northwestward velocity over the entire upper $500 \mathrm{~m}$, but with a minimum near $250 \mathrm{~m}$ (Figs. 8b,c). The wave amplitudes, determined by displacements of the $17^{\circ} \mathrm{C}$ isotherm from its equilibrium position, were 95 and $55 \mathrm{~m}$ for the a- and b-waves at mooring $\mathrm{N}$, and $60 \mathrm{~m}$ for the a-waves at mooring $\mathrm{S}$. The peak northwestward currents in the upper layer were $65 \mathrm{~cm} \mathrm{~s}^{-1}$ for both the a- and b-waves at mooring $\mathrm{N}$, and $65 \mathrm{~cm} \mathrm{~s}^{-1}$ for the a-waves at mooring $\mathrm{S}$. The waves were broader and less steep than waves observed farther to the west on the continental shelf and slope. This is attributable to the moorings being closer to the Luzon Strait, and the observed waves therefore having less 


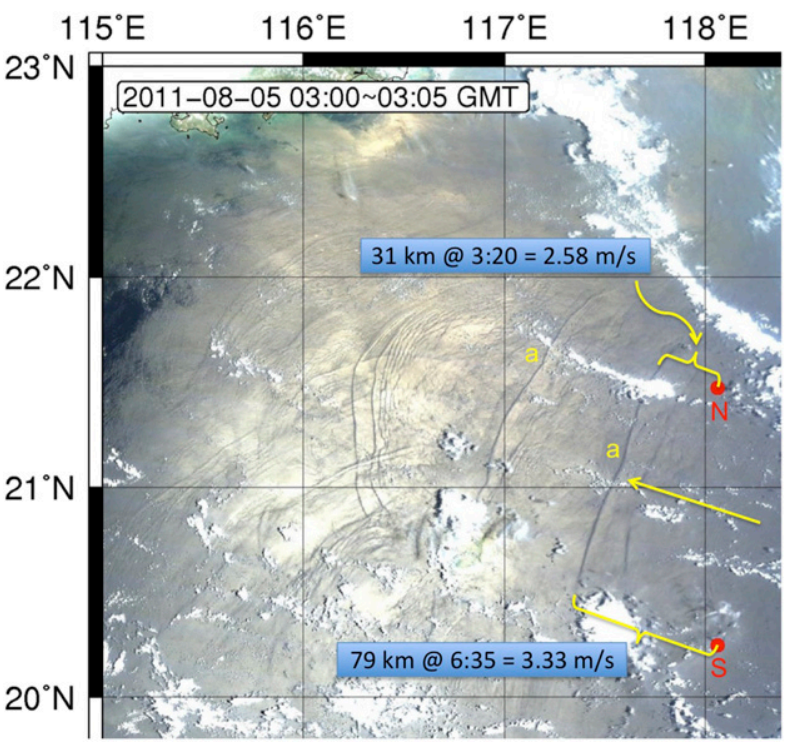

FIG. 6. MODIS optical sun glint image from 5 Aug 2011 showing an a-wave crest that had just passed moorings $\mathrm{N}$ and $\mathrm{S}$ (red dots). These waves clearly passed the southern mooring first. Propagation speeds can be computed from the time difference between the image and mooring passage. The yellow arrow indicates the direction of wave propagation. The complex wave refraction pattern visible to the left was due to Dongsha Reef, which is hidden beneath the clouds in this image.

time/distance to develop and steepen nonlinearly than waves observed farther to the west. A sensible comparison point is with Windy Islands Soliton Experiment/ Variability Around the Northern South China Sea (WISE/VANS) mooring B1 that was located along the same propagation vector as mooring $\mathrm{N}$ but in slightly deeper water to the southeast. The values observed at mooring $\mathrm{N}$ were similar in both magnitude and direction to those observed at B1 (Ramp et al. 2010).

September 4 featured a steep b-wave at mooring $\mathrm{N}$, a broader b-wave at mooring $\mathrm{S}$, and no a-waves at either mooring (Fig. 9). The southern b-wave was barely distinguishable from the nonlinear internal tide but can be identified unambiguously from the arrival patterns in Fig. 5. This time the b-wave at mooring $\mathrm{N}$ showed a clear mode- 1 structure with a nodal point similar to the 16 July a-wave. While not obvious in the temperature plot, the b-wave was actually a threewave packet that was clearly visible in the velocity plot for mooring $\mathrm{N}$. These mooring $\mathrm{S}$ waves were very weak compared with the mooring $\mathrm{N}$ waves, apparently near the southernmost extent of the wave. The wave amplitudes were $80 \mathrm{~m}$ at mooring $\mathrm{N}$ but only $30 \mathrm{~m}$ at mooring $\mathrm{S}$. The upper-layer currents were also much weaker at $\mathrm{S}$, about 50 and $30 \mathrm{~cm} \mathrm{~s}^{-1}$ for moorings $\mathrm{N}$ and $\mathrm{S}$, respectively.

\section{c. Mesoscale eddy effects}

The basic wave geometries can explain many of the features of the arrival patterns described above at moorings $\mathrm{N}$ and $\mathrm{S}$. Two features which remain puzzling are 1) that the waves arrived about $45 \mathrm{~min}$ earlier at mooring $\mathrm{S}$ versus mooring $\mathrm{N}$ for clusters 1 and 2 than for clusters 3 and 4, and 2) the complete lack of a-waves during cluster 5 . These features can be understood by examining the background mesoscale flow relative to the moored observations (Figs. 10, 11). The satellite altimetry shows that two anticyclonic warm-core eddies passed over the moorings during the experiment. The first (AC1) was the smaller and stronger of the two and passed directly between the two moorings forcing eastward currents at mooring $\mathrm{N}$ and westward at mooring $S$ (Fig. 10a). The eddy was clearly observed in the low-pass-filtered currents (Fig. 11) that were $40 \mathrm{~cm} \mathrm{~s}^{-1}$ eastward at mooring $\mathrm{N}$ and likewise $40 \mathrm{~cm} \mathrm{~s}^{-1}$ westward at mooring $\mathrm{S}$. The eddy translated southwestward at about $6 \mathrm{~km} \mathrm{day}^{-1}$ following the strike of the continental slope (Figs. 10b,c). For this reason, it cleared mooring $\mathrm{N}$ first on about 24 July, while the eddy currents lingered until 17 August at mooring S (Figs. 11a,c). These mesoscale currents would advect the internal waves favorably westward at mooring $\mathrm{S}$, causing them to arrive earlier, and would retard them at mooring $\mathrm{N}$, causing them to arrive later, increasing the time difference for the wave arrivals between moorings. Indeed, this explains the average difference in arrival time between moorings $\mathrm{S}$ and $\mathrm{N}$ prior to 24 July when the eddy was present that was $4 \mathrm{~h} 15 \mathrm{~min}$ versus $3 \mathrm{~h} 33 \mathrm{~min}$ after that day when the eddy had moved away.

The large, oblong eddy AC2 (Fig. 10d) may also contribute to the complete lack of a-waves at either mooring during cluster 5. This eddy forced northward mean flows at both moorings, but especially mooring $\mathrm{S}$. This may have advected the a-waves northward out of the field of view. Increased horizontal shear around the edges of the eddy might also smear out or mix the wave crests, as suggested by the remnant field of ordinary internal waves (Fig. 5). Note that since the a-waves were propagating up from the south, they spent more time interacting with eddy $\mathrm{AC} 2$ than the b-waves which were propagating straight west, especially at mooring $\mathrm{N}$. Additionally since this eddy resembled a Kuroshio intrusion, it may also have refracted the wave field via the mechanism described by other authors ( $\mathrm{Li}$ et al. 2016; Park and Farmer 2013; J.-H. Park et al. 2018, unpublished manuscript). The mesoscale impacts on the PIES array are discussed in further detail in J.-H. Park et al. (2018, unpublished manuscript). 
Buoy North
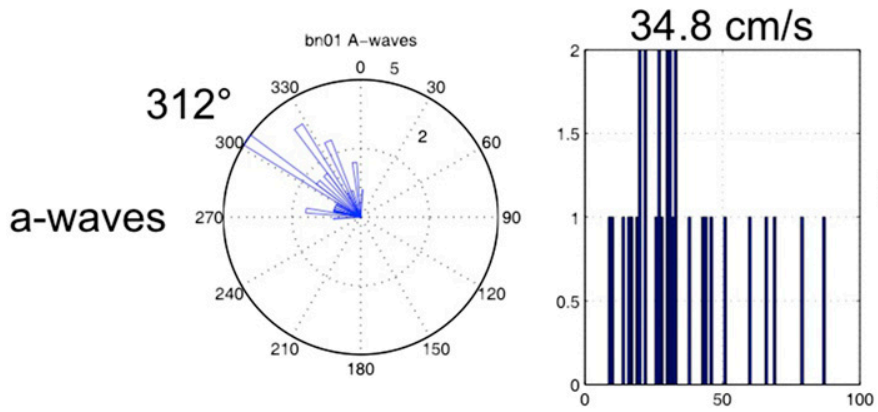

Buoy South
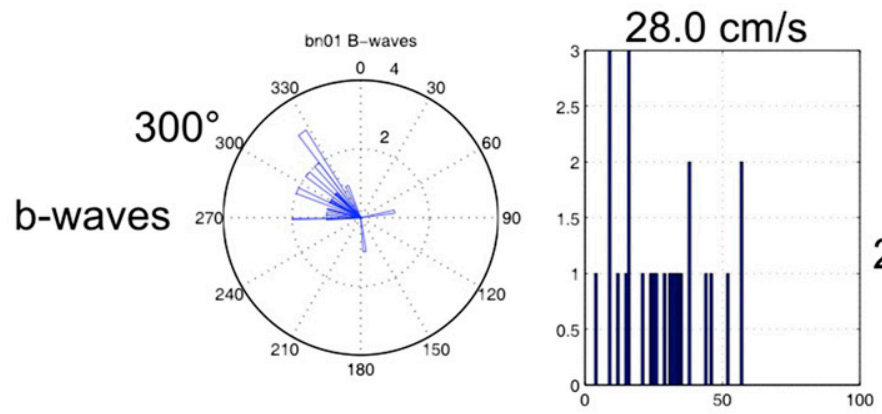
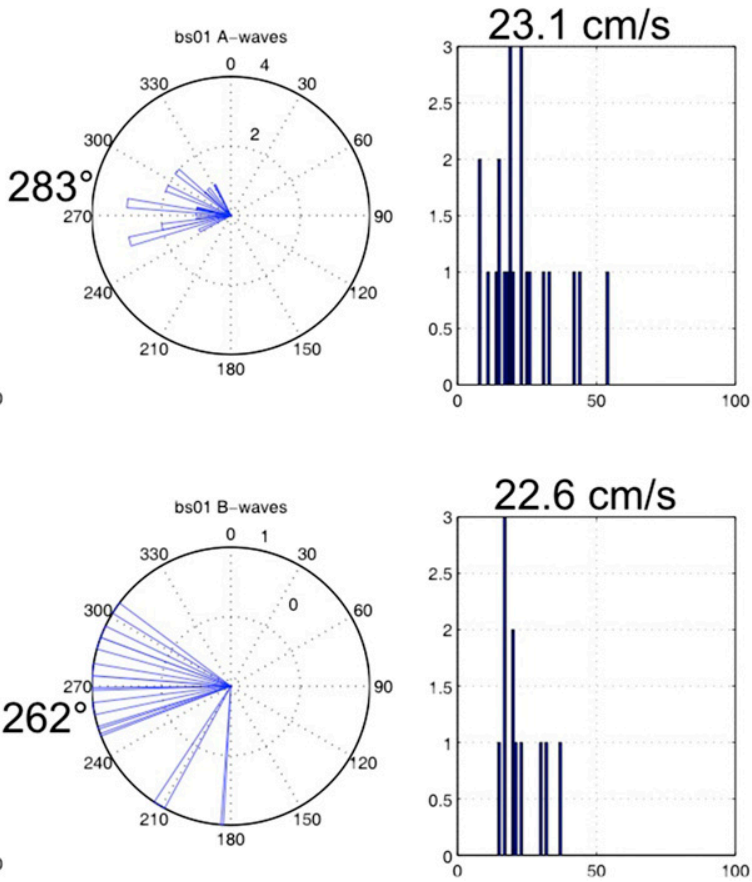

FIG. 7. Histograms of upper-layer wave speeds and directions for moorings $\mathrm{N}$ and $\mathrm{S}$. Waves are assumed to be propagating in the same direction as the upper-layer velocity. Statistically, both types of waves were stronger at mooring $\mathrm{N}$ than at mooring $\mathrm{S}$. The a-waves were collectively stronger than the b-waves at both sites and propagated $11^{\circ}-12^{\circ}$ more toward the north.

\section{d. Spatial patterns from moorings and PIES}

The wave-arrival patterns described above for the western basin can be better understood using additional information from the PIES array and the source moorings. Two complete transects were obtained from the PIES data, one in the north-south direction (instruments PM04, PM05, and PM06) and one in the east-west direction (instruments PM02, PM05, PM08, and PM11). The east-west line led directly into source mooring A1 (Fig. 1) although the time series overlapped only from 5 July to 8 August. Mooring S9 was located to the south of the PIES array but proved informative nevertheless.

The meridional variability is examined first using representative data from clusters 2 and 5 during July and August-September 2011 (Fig. 12). The NLIWs in these presentations appear as sharp downward spikes in the thermocline and were most obvious and numerous at site PM05 in the center of the array. This means that mooring PM05 was the closest to the main beam of the westward and northwestward propagating waves, a result in agreement with the satellite remote sensing (e.g., Fig. 6). To the north at PM04, the internal tide was semidiurnal and nearly sinusoidal during both time periods (Figs. 12a,d). There was little evidence of NLIWs, a curious result given the proliferation of such waves farther downstream at mooring $\mathrm{N}$. We deduce that the internal tides slowed and steepened rapidly between PM04 and mooring $\mathrm{N}$ due to the shoaling bottom topography. To the south at site PM06, the internal tide was diurnal during July but mostly semidiurnal (becoming diurnal the last few days) during August-September (Figs. 12c,f). The combination of these tides in the north and south produced two quite different wave fields during July versus AugustSeptember. In July when the internal tide was diurnal in the south, only a-waves appeared every $24 \mathrm{~h}$. The waves were well defined at PM05 but less so, more like a steep tidal front, at PM06. During August-September when the internal tide was semidiurnal in the south, both awaves and b-waves were produced at PM05 and PM06. More packet structure was evident at PM05 but a few NLIWs were also evident at PM06, as on 30 August to 1 September. Significantly, more NLIWs were produced at PM05 during times when there was a semidiurnal internal tide coming up from the south (cf. Figs. 12b and 12e). This is attributed to less rotational dispersion in the semidiurnal tide than the diurnal (Helfrich 2007; Farmer et al. 2009; Li and Farmer 2011; Farmer et al. 2011). The arrival times were similar during both July and September: there was no discernable phase lag between 


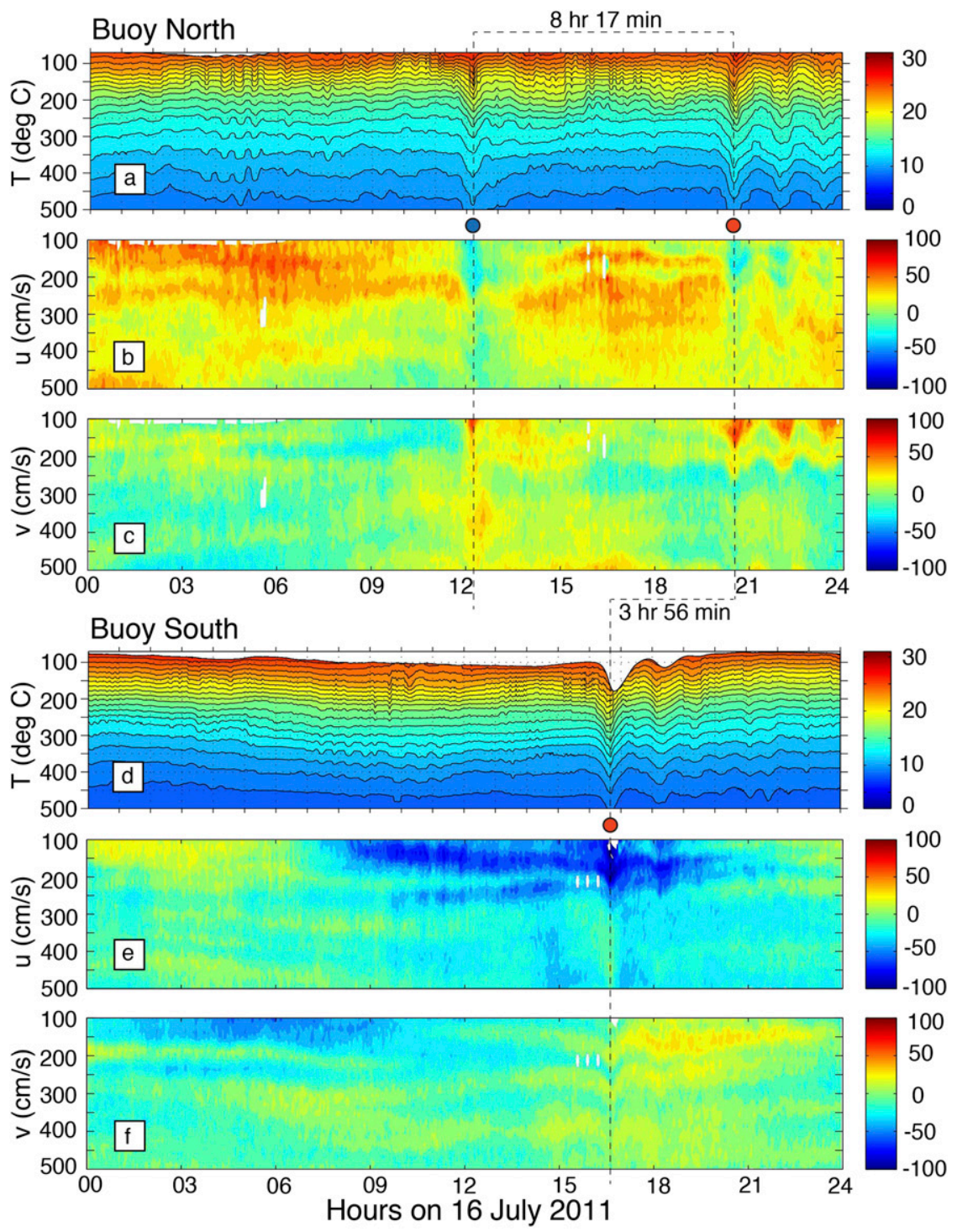

FIG. 8. Temperature, east-west $(u)$ current component, and north-south $(v)$ current component contours for the upper $500 \mathrm{~m}$ from moorings (a)-(c) $\mathrm{N}$ and (d)-(f) S on $16 \mathrm{Jul}$ 2011. This wave is from cluster 2, (fourth panel down from the top in Fig. 3). The a- and b-waves are indicated by red and blue dots, respectively. Here, a- and b-waves are visible at mooring $\mathrm{N}$, but the b-wave was absent at mooring $\mathrm{S}$.

PM05 and PM06. Despite the lack of waves at PM04, the beat of the internal tide can be easily seen, which lagged behind PM05 and PM06 by about $2.5 \mathrm{~h}$. Like at moorings $\mathrm{N}$ and $\mathrm{S}$, this can be accounted for by the tilt of the westward-propagating wave fronts.

To study the zonal changes as the tides and waves crossed the basin, the July time period is considered first since the source moorings were still in the water. To help understand processes near the source, the zonal component of the observed barotropic tide is displayed across the bottom (Figs. 13g,h). The tides were mixed at both sites, but more semidiurnal at A1. This was typical of all the time series collected near the ridges where the semidiurnal flux greatly exceeded the diurnal at the A-line and vice versa at the S-line (Pickering et al. 2015). The tidal currents were asymmetric with stronger currents toward the east. This has also been observed previously for a site between Batan and Itbayat Island (Ramp et al. 2010). The mixed, asymmetric barotropic tide resulted in one strong eastward current per day at both A1 and S9. The barotropic currents were almost exactly in phase at the two sites. Associated with this eastward pulse, there was an internal tide of elevation that appeared at site PM11 just $4 \mathrm{~h}$ later, indicating a propagation speed of $2.71 \mathrm{~m} \mathrm{~s}^{-1}$ (Fig. 13f). To 

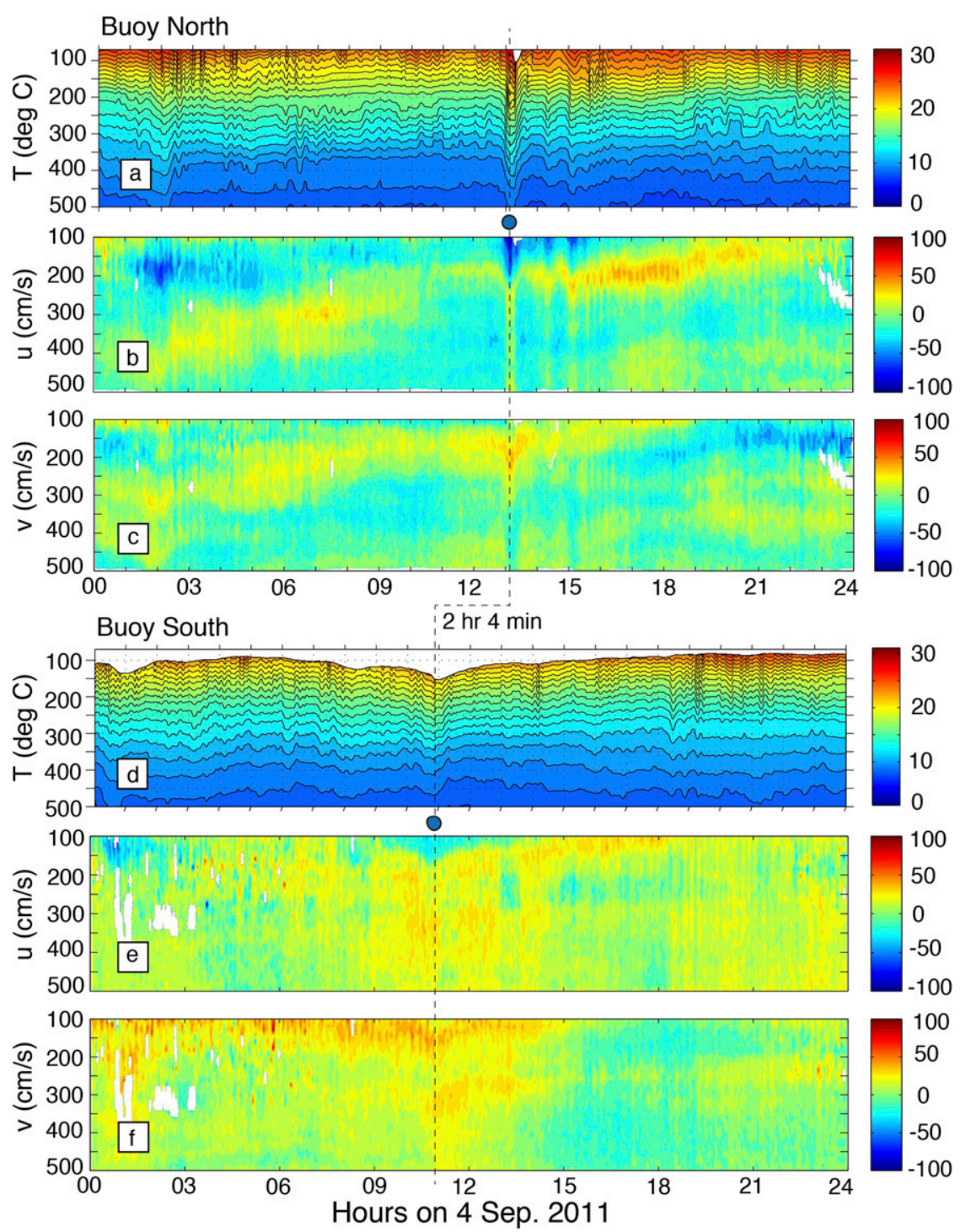

FIG. 9. As in Fig. 8, but for 4 Sep 2011. The a-waves were absent on this day, which shows the arrival-time difference between the b-waves, indicated by the blue dots and dashed lines. This wave is from cluster 5 (third panel up from the bottom in Fig. 5).

the west, saw tooth or "corner" waves had developed by PM08, a sign of increasing steepening and nonlinearity (Li and Farmer 2011). The elevation waves from PM11 steepened on the back side, extending down into the trough behind them. By PM05 the a-waves were well developed, extending farther downward out of the troughs (Fig. 13d). These waves continued to propagate westward past PM02 with little change of form. The waves can easily be tracked from PM05 to PM02 using an average propagation speed of $3.56 \mathrm{~m} \mathrm{~s}^{-1}$. Also at PM02, a second tidal front which eventually became the b-waves appeared via steepening of the back side of the intermediate tidal beat (Fig. 13c, black arrows). This front did not appear until
$180 \mathrm{~km}$ west of the ridge versus almost immediately for the a-wave front. The b-waves did not manifest themselves at mooring $\mathrm{S}$ but did appear as weak NLIWs at mooring $\mathrm{N}$ on 16-18 June (Fig. 13a, see also Fig. 3). Recall that moorings $\mathrm{N}$ and $\mathrm{S}$ were located off track relative to the PM02 to A1 line, but this can be accounted for by the wave geometry. The propagation time from PM05 to S was $13.49 \mathrm{~h}$, and was $15.49 \mathrm{~h}$ to mooring $\mathrm{N}$ for the $\mathrm{b}$-waves and $17.49 \mathrm{~h}$ for the a-waves. A few of the weak b-waves at mooring $\mathrm{N}$ are also highlighted by the black arrows.

Despite the lack of source moorings, the transbasin thermal displacements are instructive for the AugustSeptember time period as well (Fig. 14). Given the 


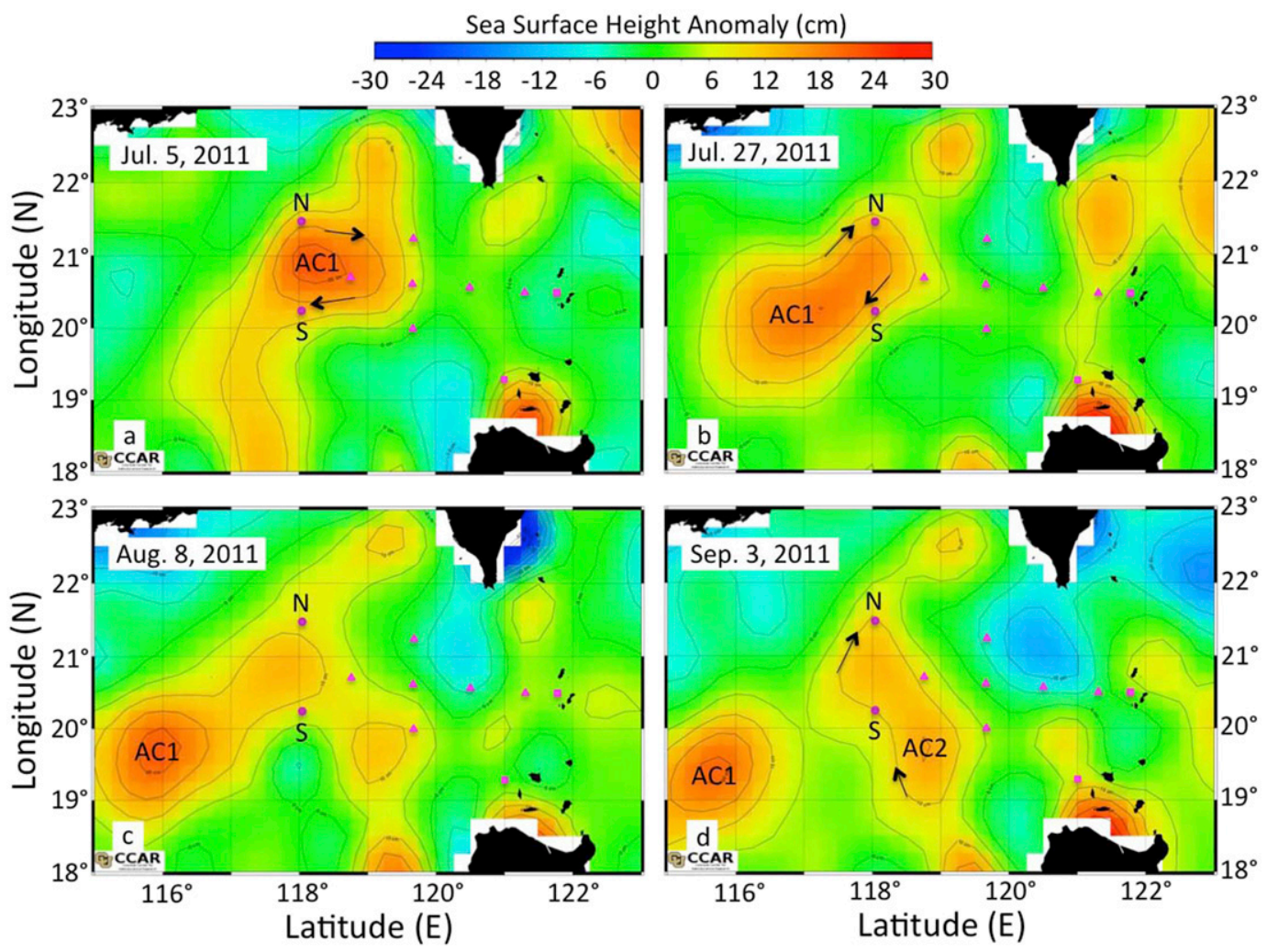

FIG. 10. Four snapshots of the sea surface height anomaly based on consolidated satellite altimetric datasets on file at the Colorado Center for Astrodynamics Research. The orange shades represent altimetric highs caused by anticyclonic warm-core rings, and vice versa for the blue tones. Black arrows indicate the direction of flow (not to scale). Two warm eddies, referred to here as $\mathrm{AC} 1$ and $\mathrm{AC} 2$, interacted with moorings $\mathrm{N}$ and $\mathrm{S}$. Red circles indicate the basin moorings, triangles show the PIES array, and squares indicate the source moorings. The snapshots are for (a) 5 Jul, (b) $27 \mathrm{Jul}$, (c) 8 Aug, and (d) 3 Sep 2011.

strong correlation between PM11 and the barotropic tide at A1 (Figs. 13f,g) it can reasonably be assumed that the pattern at PM11 during August-September mimicked the tide at A1 as well. During this time frame, the internal tide at PM11 (and likely the BT tide at A1) was semidiurnal with little fortnightly variation. This time, the elevation tide at PM11 steepened at the back and formed a front for both a- and b-waves. The saw tooth waves first appeared at PM08, and the deep troughs spawned waves of depression for both types of NLIW, clearly visible at PM02 and PM05 (Figs. 14c,d). A few of the b-waves are highlighted by dashed lines to illustrate the propagation pattern. The figure shows dramatically how the a-waves all disappeared between PM02 and the moorings (Figs. 14a,b). This provides additional evidence that eddy AC2 disrupted the wave growth in this region.

Clearly, the spatial distribution of the diurnal and semidiurnal internal tide is important to determining how the wave field generated in the east will evolve downstream. This distribution is summarized for the four major tidal constituents $\mathrm{K} 1, \mathrm{O} 1, \mathrm{M} 2$, and $\mathrm{S} 2$ in Table 2. Across the entire array, the diurnal energy is increasing southward while the semidiurnal constituents are larger toward the north. This is the expected result given the Luzon Strait East Ridge topography, which favors semidiurnal conversion to the north and diurnal to the south (Zhang et al. 2011) but has not been previously demonstrated using field data. There was no discernable east-west trend in the diurnal tidal amplitudes, while the semidiurnal decreased from east to west. This may be due to more energy being converted to higher frequencies (i.e., NLIWs) as the semidiurnal internal tides propagated from east to west. The results of these complex spatial interactions on the internal tides and waves are now examined further using a numerical model.

\section{Discussion}

While the observations are enlightening by themselves, a more complete, gap-free plan view of the wave crests as 

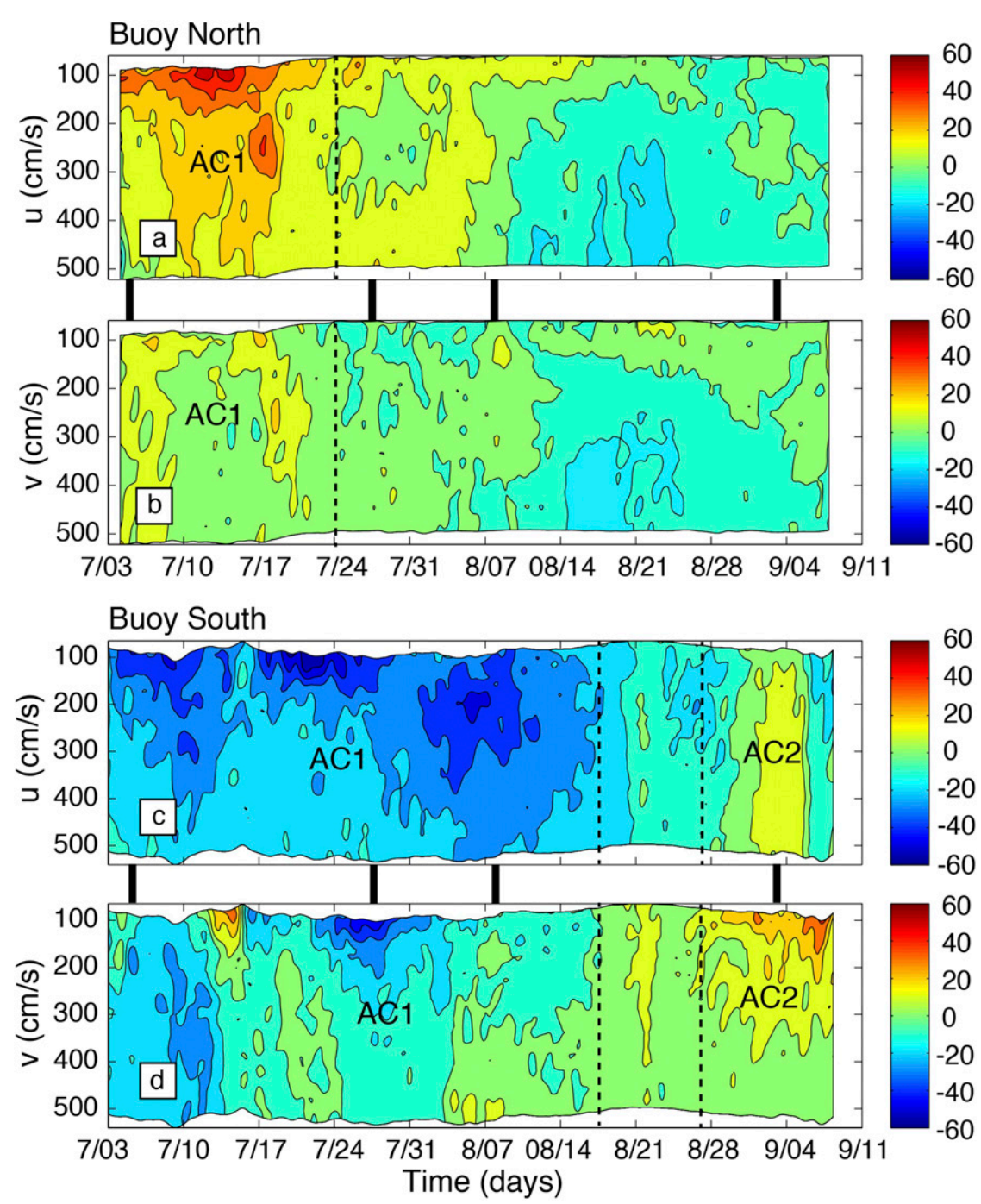

FIG. 11. Low-pass-filtered currents at buoy (a),(b) N and (c),(d) S for the duration of the array. Black bars indicate the times of the altimetric snapshots shown in Fig. 10. Vertical dashed lines indicate approximate eddy boundaries. The currents forced by eddies AC1 and AC2 are labeled.

they cross the deep basin can be obtained via a numerical model. In this case, the SUNTANS model was used (Fringer et al. 2006). The model was implemented in the region spanning $18^{\circ}-23^{\circ} \mathrm{N}, 115^{\circ}-125^{\circ} \mathrm{E}$ and used 255883 unstructured grid cells to obtain high resolution in the vicinity of abrupt topography, especially surrounding the East Ridge in the Luzon Strait. The initial condition for stratification was spatially homogeneous and derived from historical CTD casts. This model run therefore does not account for mesoscale variability. The model has been previously applied to the region with good results (Zhang et al. 2011). In the present application, we benefit from having a spatial array of observations to compare with and focus especially on the spatial variability of the thermocline displacements. In general, wave arrival times in the model agreed very well with the observations while wave amplitudes were harder to predict, similar to Zhang et al. (2011). More detailed information on the model implementation and model/ data comparisons may be found in J.-H. Park et al. (2018, unpublished manuscript).

As already suggested by the observations, the origins of the a- and b-waves result from a complex threedimensional interaction of the largely semidiurnal internal tide in the northern Luzon Strait and the dominantly diurnal internal tide in the south. This results from the bottom topography along the East Ridge, which favors greater conversion to the diurnal internal 

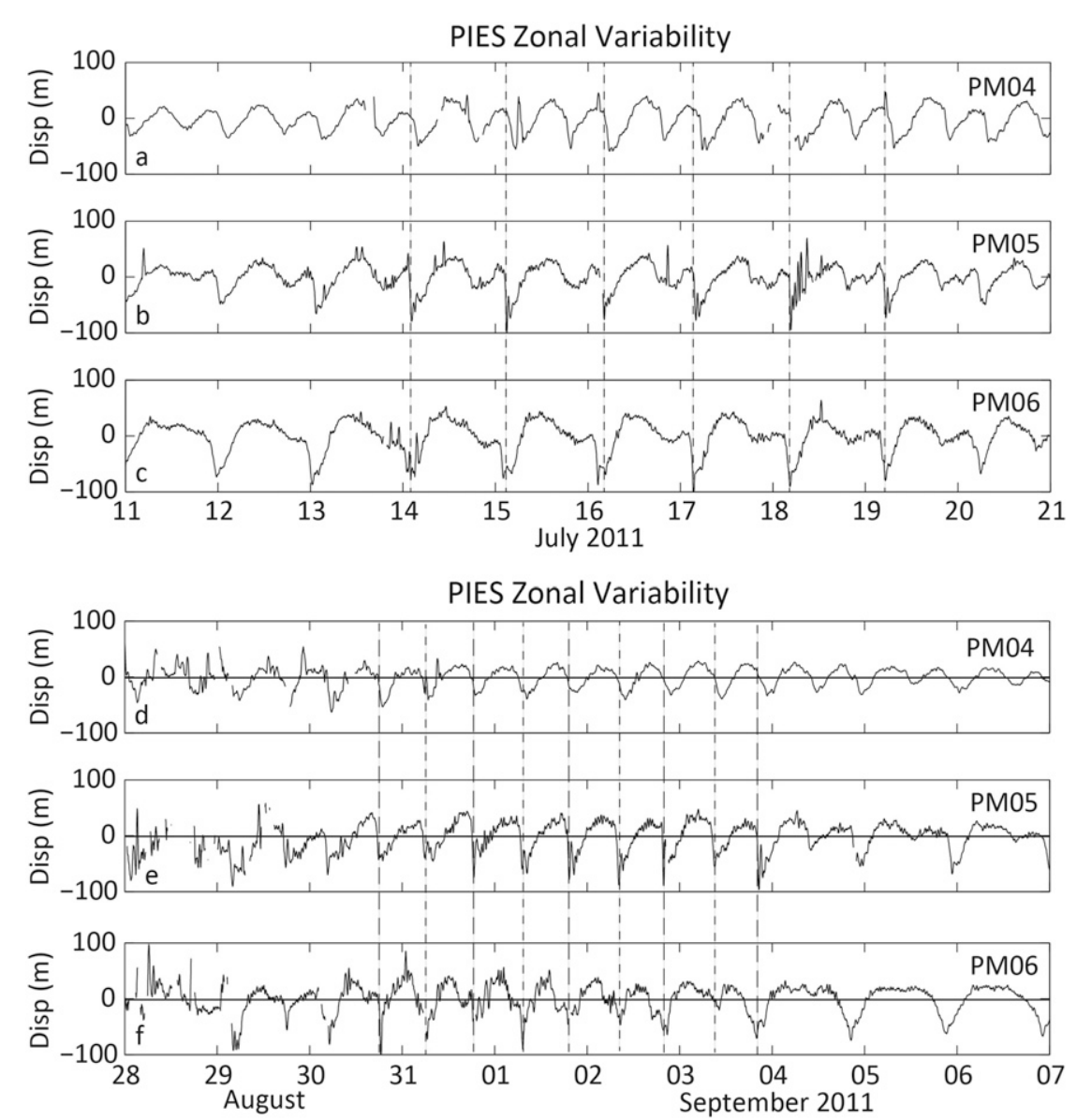

FIG. 12. Thermocline displacements observed by the PIES along $119^{\circ} 40^{\prime} \mathrm{E}$ from $21^{\circ} 15^{\prime} \mathrm{N}$ (PM04) to $20^{\circ} 00^{\prime} \mathrm{N}$ (PM06) during (a)-(c) 11-21 Jul and (d)-(f) from 28 Aug to 7 Sep 2011. To provide some temporal reference points, the a-wave and b-wave arrival times at PM05 are highlighted with short-dashed and long-dashed lines, respectively. Displacements are computed from PIES travel times as described in the text.

tide in the south and semidiurnal to the north (Zhang et al. 2011; Pickering et al. 2015). The complex phasing between the diurnal and semidiurnal internal tides results in changing patterns in the basin between the east and west ridges (Fig. 15). When the central water along $121^{\circ} \mathrm{E}$ between $20^{\circ}$ and $21^{\circ} \mathrm{N}$ is in phase with the water to the south (Figs. 15a,c,e,g) an a-wave is released which propagates WNW. This wave crosses the deep part of the western ridge, suffers very little dissipation, and is not refracted off its original path. When the tide in the central water is in phase with the water to the north (Figs. 15b,d,f,h) a b-wave is released. This wave crosses the shallow part of the western ridge where it is refracted parallel to the ridge and suffers large losses due to dissipation (Alford et al. 2011; Buijsman et al. 2012, 2014; Pickering et al. 2015). This is why the b-waves travel westward rather than northwestward, are weaker than the a-waves, and require more time/distance to be spawned from the internal tide. In fact, many b-waves do not appear at all until the tide starts shoaling up the continental slope (Ramp et al. 2018, manuscript submitted to Nonlinear Processes Geophys.).

The internal tides are in phase at A1 and S9 (recall Figs. 13g,h) and both a- and b-waves form on the back side of an internal tide of elevation associated with the maximum eastward (ebb) tide. Both types of waves are released diurnally on every other beat of the semidiurnal tide, but are staggered so that the process appears semidiurnal. If a large diurnal variation exists, the a-wave is associated with the larger beat. If not, then both types of waves begin life with roughly equal amplitude. This release pattern would result in a wave every twelve hours, but in fact the b-waves typically lead the a-waves by only $10 \mathrm{~h}$ in the basin since the mean travel time for b-waves across shallower topography (the West Ridge) in the near field is slower than for the 

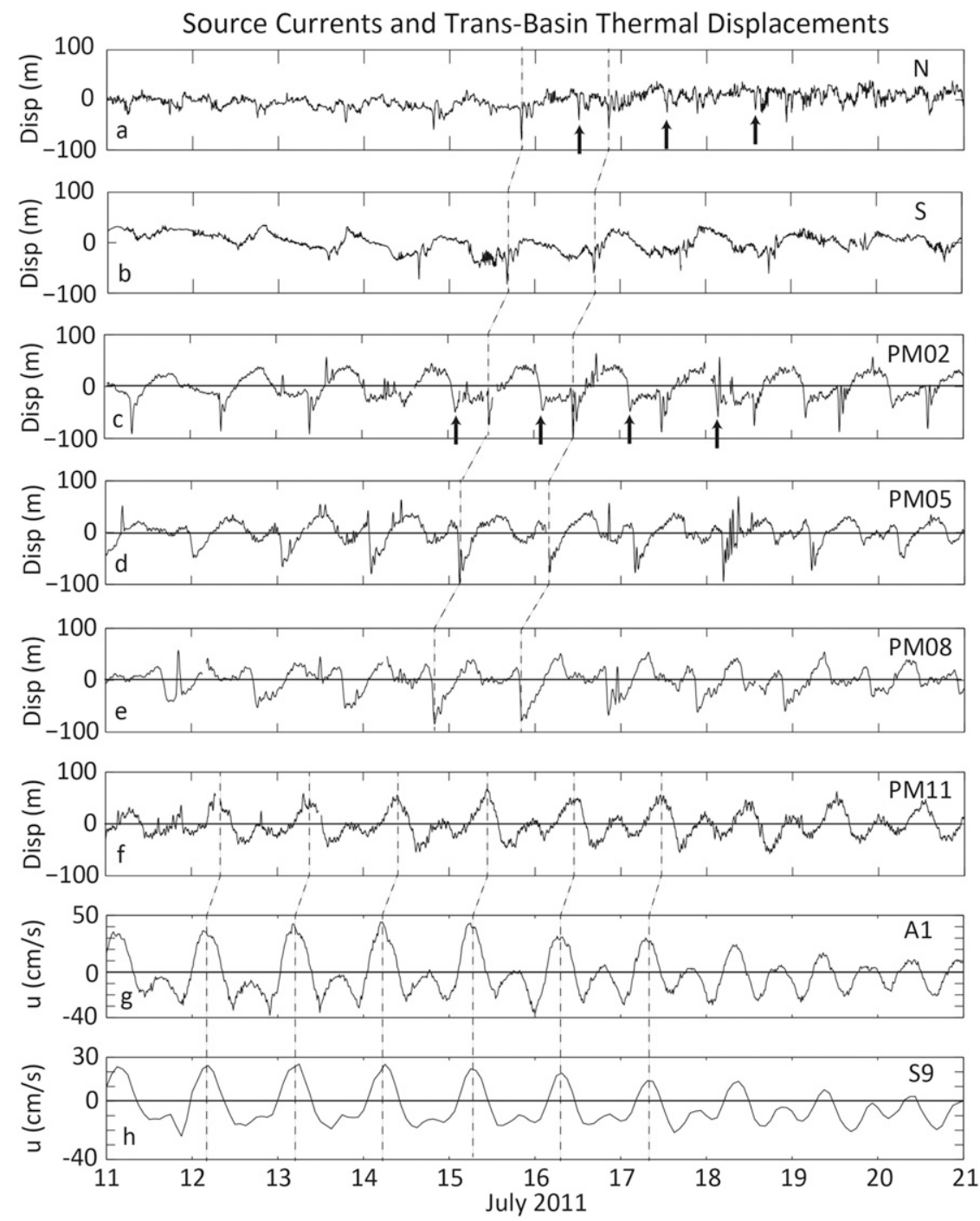

FIG. 13. Meridional variation of across-basin thermal structure as indicated by (a),(b) moorings $\mathrm{N}$ and S, (c)-(f) the PIES array, and (g),(h) moorings A1 and S9. For moorings $\mathrm{N}$ and S, this is the vertical displacement of the $20^{\circ} \mathrm{C}$ isotherm. The PIES displacements are thermocline displacements as described in the text. For the source moorings A1 and S9, the zonal component of the barotropic (vertically averaged) currents is shown. The short-dashed lines are used as a point of reference for a few sets of a-waves. Crests are highlighted near the source and troughs west of the western ridge. The short black arrows highlight a few b-waves at $\mathrm{N}$ and $\mathrm{PM} 02$.

a-waves in the south, which allows the a-waves to catch up. Furthermore, the lead time in the model for b-waves ahead of a-waves decreases southward due to the convergence of the wave fronts resulting from the different propagation angles.

Many features of the a- and b-waves, which have been observed both here and in previous experiments, can now be understood in light of the two-source scenario. These include 1) the propagation direction, in which a-waves are always observed to propagate northwestward, while the b-waves propagate almost straight west; 2) the b-waves leading the a-waves; and 3) the a-waves more energetic than the b-waves. Synonymous with the third feature is that the a-waves tend to form earlier/closer to the source than b-waves and are more likely to form packets. The propagation direction is determined by the orientation of the generating topography in the Luzon Strait, by having two separate sources separated by $1.5^{\circ}$ of latitude, and because the b-waves are refracted to align with the shallow portion of the West Ridge (north 

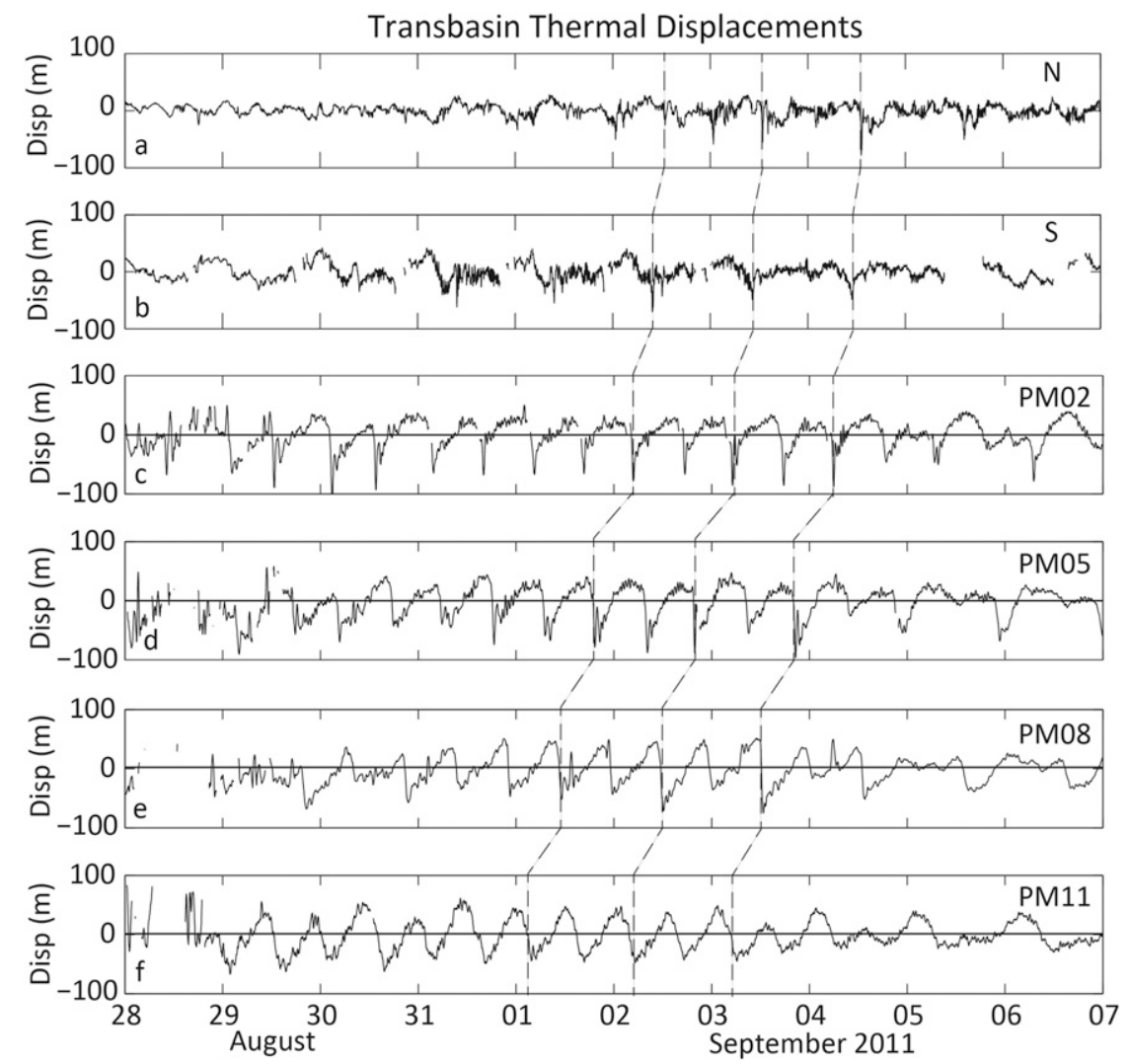

FIG. 14. As in Fig. 13, but from 28 Aug to 7 Sep 2011. The bottom two panels have been eliminated because the source moorings were no longer in the water. The long-dashed lines trace three b-waves across the basin.

of $20.6^{\circ} \mathrm{N}$ ) and the a-waves are not. The b-waves experience large dissipation over the West Ridge and the a-waves do not, making them generally less energetic. These weaker waves then require more distance/time to grow nonlinearly and spawn NLIWs. There are exceptions to this: very large b-waves do form occasionally and may subsequently form packets. The smaller lead time for the b-waves versus the a-waves in the south versus the north is observable in both the moorings and the PIES (cf. Figs. 4 and 15) and is due to the different propagation directions.

Other model results cannot be verified by the field data. We cannot observe the smaller lead time for the b- versus a-waves at the southern mooring since there were so few cycles when both wave types were observed. Both Zhang et al. (2011) and the more recent model runs presented here suggest that $b$-wave crests should extend farther south than a-wave crests due to their more southward propagation direction. This was not observed as many more a-waves were observed than b-waves even at mooring S. A close study of Fig. 14 suggests this may be because the tidal front that eventually spawns the b-waves was shorter zonally at its inception than the a-wave front. The a-wave front stemmed from two sources in the south that quickly merged together to form a greater along-crest distance for the a-waves. This characteristic is also a function of longitude. Near the sources, say along $120^{\circ} \mathrm{E}$, the a-wave crests are obviously farther south than the b-wave crests since they are generated there. The wave crests cross in the model at some point. Finally, the fortnight-to-fortnight variability between clusters that was ascribed to mesoscale variability cannot be accounted for by this model run which did not include these effects. For more detail on the mesoscale impacts, the reader is referred to J.-H. Park et al. (2018, unpublished manuscript).

What does all this mean for the wave generation problem? While the observations do not focus on this, some useful information can be deduced. Both observations and model show that both types of waves evolve when the back side of an internal tide of elevation steepens drastically upon being released from the ridge complex. The elevation forms during the maximum ebb (toward the Pacific) tide and is released when the tide turns. The results are in agreement with the tidal release mechanism (Buijsman et al. 2010a) in which strong 
TABLE 2. Spatial distribution of tidal constituents from the PIES array, giving internal tidal amplitudes (“Amp”; m) and phase $\left(^{\circ}\right)$ for the principal diurnal (K1 and O1) and semidiurnal (M2 and S2) constituents.

\begin{tabular}{|c|c|c|c|c|c|c|c|c|}
\hline & \multicolumn{2}{|c|}{$\mathrm{K} 1$} & \multicolumn{2}{|c|}{$\mathrm{O} 1$} & \multicolumn{2}{|c|}{ M2 } & \multicolumn{2}{|c|}{ S2 } \\
\hline & Amp & Phase & Amp & Phase & Amp & Phase & Amp & Phase \\
\hline \multicolumn{9}{|c|}{ Line north } \\
\hline PM07 & 7.54 & 297 & 6.11 & 246 & 26.96 & 166 & 10.3 & 203 \\
\hline PM04 & 5.33 & 52 & 4.29 & 342 & 20.64 & 11.25 & 6.44 & 52 \\
\hline \multicolumn{9}{|c|}{ Line middle } \\
\hline PM11 & 10.03 & 325 & 6.94 & 287 & 21.91 & 287 & 10.27 & 317 \\
\hline PM08 & 13.42 & 348 & 9.34 & 284 & 12.24 & 120 & 5.47 & 172 \\
\hline PM05 & 12.4 & 58 & 7.38 & 348 & 14.41 & 331 & 5.66 & 36 \\
\hline PM02 & 13.41 & 142 & 6.96 & 81 & 10.5 & 204 & 4.15 & 280 \\
\hline \multicolumn{9}{|c|}{ Line south } \\
\hline PM12 & 20.66 & 308 & 16.13 & 260 & 20.83 & 271 & 9.75 & 310 \\
\hline PM06 & 18.6 & 51 & 11.87 & 356 & 16.5 & 303 & 5.97 & 6 \\
\hline \multicolumn{9}{|c|}{ From north to south } \\
\hline PM04 & 5.33 & 52 & 4.29 & 342 & 20.64 & 11.25 & 6.44 & 52 \\
\hline PM05 & 12.4 & 58 & 7.38 & 348 & 14.41 & 331 & 5.66 & 36 \\
\hline PM06 & 18.6 & 51 & 11.87 & 356 & 16.5 & 303 & 5.97 & 6 \\
\hline
\end{tabular}

eastward currents generate westward propagating solitons. The strong eastward current creates an elevation wave on the west side of the ridge and a depression wave on the eastern side. These waves are then "released" as the tide turns. The internal tide then steepens nonlinearly as it propagates westward, and eventually spawns NLIWs in the manor best described in $\mathrm{Li}$ and Farmer (2011, their Fig. 17) for a mixed tide. The process is the same for both types of waves. The primary difference between the two is the refraction and high dissipative losses experienced by the internal tide as it crosses the northern West Ridge that cause the b-waves to be weaker and more westward than the a-waves.

\section{Conclusions}

A team of investigators deployed multiple instruments in the South China Sea during summer 2011 to observe the spatial variability of NLIW patterns from near the supposed sources (near field) to the deep basin (far field). The approach differed significantly from previous observational work which always focused along a single transect due to resource limitations. The result, combined with a three-dimensional nonhydrostatic numerical model, provides new insights on the spatial variability and propagation characteristics of the NLIWs in the South China Sea.

Data from current-meter moorings near the source, an array of 12 pressure sensor-equipped inverted echo sounders in the deep basin, and additional current-meter moorings in the far field were integrated to produce a coherent picture of the wave propagation patterns. The most significant result is that the high-frequency NLIW can be unambiguously attributed to two separate sources, one in the northern Luzon Strait centered near $21^{\circ} \mathrm{N}$, and the other centered near $19^{\circ} 45^{\prime} \mathrm{N}$ in the south. The a-waves, previously described by many authors, originate at the southern source, and the b-waves originate from the north. Both types of waves are generated by eastward flow across the ridges on the ebb tide, and are released when the tide turns (the release mechanism). The primary difference between the waves, in addition to their different locations, is that the b-waves must cross the shallow part of the western ridge, where they are refracted parallel to the ridge crest and experience large dissipative losses. The a-waves follow their natural propagation direction and experience no such losses. This is why the a-waves are almost always more energetic than the b-waves.

The above scenario has been demonstrated by examining the arrival-time differences for a- and b-waves at different locations and between the two at the same location. The b-waves are released when the tide in the central portion of the Luzon Strait is in phase with the tide to the north. The a-waves are released when the tide in the central portion of the strait is in phase with the tide to the south. This is also the stronger beat of the tide when the diurnal equality exists, which also contributes to the a-waves being stronger. Given the above, the time difference between the waves at generation would be nominally twelve hours. The data, however, show that the b-waves always lead the a-waves due to several factors. First, the b-waves propagate through shallower (and therefore slower) water in the near field, which allows the a-waves to catch up. The lead time is then around ten hours. Second, the wave crests converge due to their different propagation angles, further reducing the b-wave lead time, especially in the south.

Many previous authors have observed even smaller lead times for the b-waves ahead of the a-waves, on the order of 6-8 $\mathrm{h}$ farther west over the upper continental slope and shelf. This is because the northern part of the b-waves reaches shallower water sooner than the a-waves, whose propagation direction is more normal to the topography. This slows down the b-waves even more and results in the lead times observed there. This timing is coincidentally similar to the difference between the flood and ebb semidiurnal tide, which is what led previous authors, including these authors, to erroneously favor the flood tide/ebb tide generation scenario.

The wave-arrival patterns in the South China Sea may be further modified by the background mesoscale currents, which primarily take the form of eddies and the Kuroshio intrusion. It is shown here for one very simple 

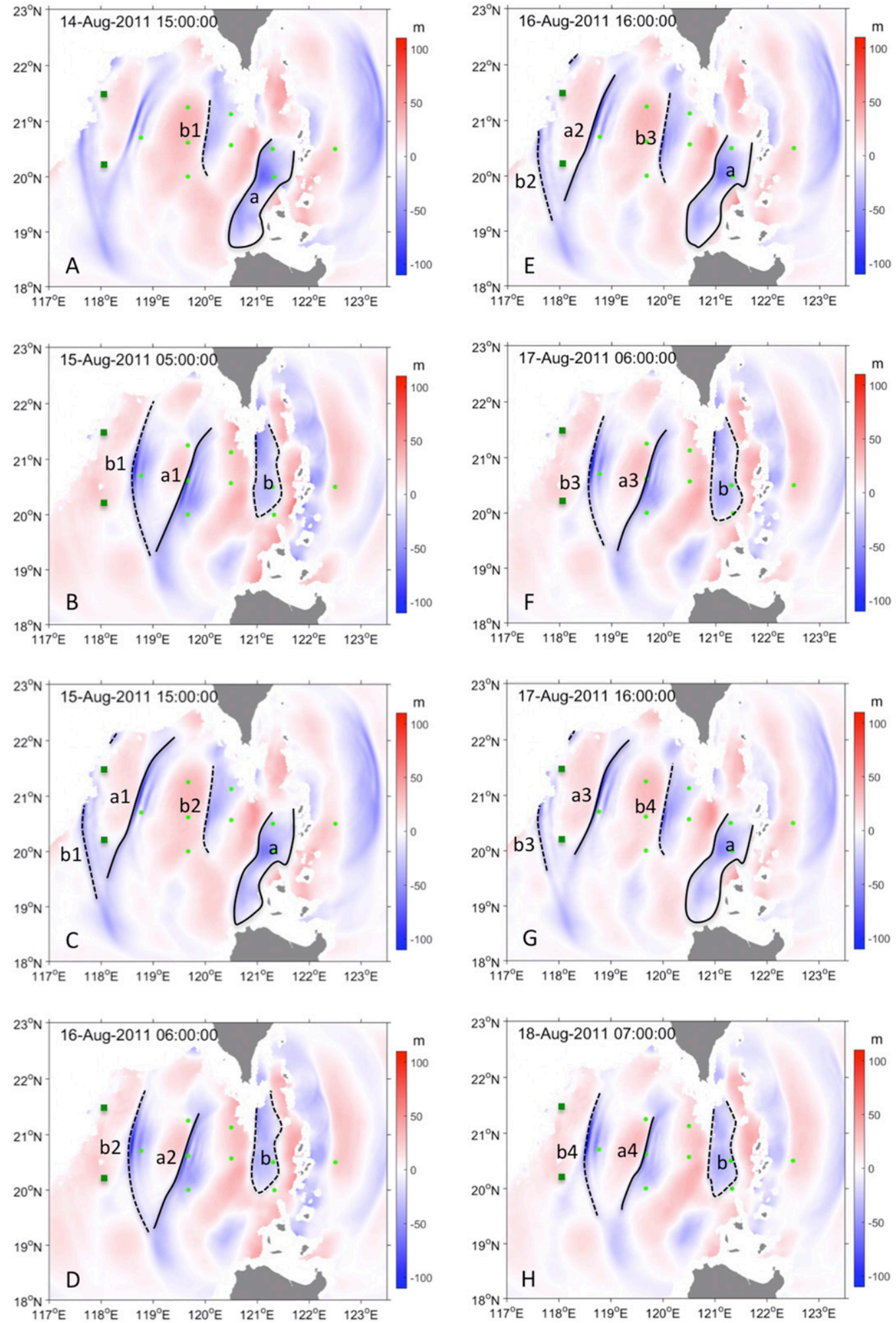

FIG. 15. Vertical displacements of the thermocline derived from the SUNTANS model. Model outputs were used to compute acoustic echo times, which were then converted to thermocline displacements. Elevations are red, and depressions are blue. The a-waves emanating from the southern portion of the Luzon Strait and propagating northwestward are indicated by solid lines. The b-waves emanating from the northern strait and propagating westward are indicated by dashed lines. The time between panels alternates between 10 and $14 \mathrm{~h}$, corresponding to the release times of the waves. Green dots indicate the PIES that were used in the model-data comparisons [see Fig. 1 and J.-H. Park et al. (2018, unpublished manuscript)]. Green squares indicate the basin moorings. 
case that an anticyclonic warm-core eddy located directly between moorings $\mathrm{N}$ and $\mathrm{S}$ increased the arrival-time difference between moorings by about $45 \mathrm{~min}$ due to eastward currents at $\mathrm{N}$ and westward currents at S. Meridional currents due to a second large, oblong warm eddy located between the moorings and the PIES array in late August somehow sheared or advected away the signal for all the a-waves at the moorings. Detailed analysis of the mesoscale effects is not our purpose here and is taken up using a much longer time series and other numerical models in a companion paper (J.-H. Park et al. 2018, unpublished manuscript).

It now seems like a detailed knowledge of the barotropic tide in the Luzon Strait would allow a good start to predicting wave-arrival patterns in the far field. This could easily be obtained using an array of inexpensive pressure gauges among the Batan Islands reporting in real time. Fine-tuning the arrival time, however, still requires a detailed knowledge of the stratification and mesoscale variability along the propagation path. This demands a much more sophisticated numerical model, likely with data assimilation.

Acknowledgments. The officers and crew of the research vessels Roger Revelle, Ocean Researcher 1, and Ocean Researcher 3 are acknowledged for their skill and patience in deploying and recovering the moorings. The data from moorings A1 and S9 were generously provided by J. Nash (Oregon State University) and M. Alford (Scripps Institution of Oceanography). This work was supported by the U. S. Office of Naval Research Physical Oceanography Program (Code 322PO) under Grant N00014-15-1-2282 and by the Taiwanese Ministry of Science and Technology (MOST).

\section{REFERENCES}

Alford, M. H., and Coauthors, 2010: Speed and evolution of nonlinear internal waves transiting the South China Sea. J. Phys. Oceanogr., 40, 1338-1355, https://doi.org/10.1175/2010JPO4388.1.

— Strait: Two tales of two ridges. J. Phys. Oceanogr., 41, 22112222, https://doi.org/10.1175/JPO-D-11-073.1.

— waves in the South China Sea. Nature, 521, 65-69, https:// doi.org/10.1038/nature14399.

Buijsman, M. C., Y. Kanarska, and J. C. McWilliams, 2010a: On the generation and evolution of nonlinear internal waves in the South China Sea. J. Geophys. Res., 115, C02012, https:// doi.org/10.1029/2009JC005275.

— , J. C. McWilliams, and C. R. Jackson, 2010b: Eastwest asymmetry in nonlinear internal waves from Luzon Strait. J. Geophys. Res., 115, C10057, https://doi.org/10.1029/ 2009JC006004.

— S. Legg, and J. Klymak, 2012: Double-ridge internal tide interference and its effect on dissipation in Luzon Strait. J. Phys.
Oceanogr., 42, 1337-1356, https://doi.org/10.1175/JPO-D-110210.1.

— ternal tide resonance in Luzon Strait. J. Phys. Oceanogr., $\mathbf{4 4}$ 850-869, https://doi.org/10.1175/JPO-D-13-024.1.

Chen, Y.-J., D. S. Ko, and P.-T. Shaw, 2013: The generation and propagation of internal solitary waves in the South China Sea. J. Geophys. Res. Oceans, 118, 6578-6589, https://doi.org/ 10.1002/2013JC009319.

Du, T., Y.-H. Tseng, and X.-H. Yan, 2008: Impacts of tidal currents and Kuroshio intrusion on the generation of nonlinear internal waves in Luzon Strait. J. Geophys. Res., 113, C08015, https:// doi.org/10.1029/2007JC004294.

Duda, T. F., J. F. Lynch, J. D. Irish, R. C. Beardsley, S. R. Ramp, C.-S. Chiu, T.-Y. Tang, and Y.-J. Yang, 2004: Internal tide and nonlinear internal wave behavior at the continental slope in the northern South China Sea. IEEE J. Oceanic Eng., 29, 1105-1131, https://doi.org/10.1109/JOE.2004.836998.

Farmer, D., Q. Li, and J.-H. Park, 2009: Internal wave observations in the South China Sea: The role of rotation and non-linearity. Atmos.-Ocean, 47, 267-280, https://doi.org/10.3137/OC313.2009.

Farmer, D. M., M. H. Alford, R.-C. Lien, Y. J. Yang, M.-H. Chang, and Q. Li, 2011: From Luzon Strait to the Dongsha Plateau: Stages in the life of an internal wave. Oceanography, 24, 64-77, https://doi.org/10.5670/oceanog.2011.95.

Fringer, O. B., M. Gerritsen, and R. L. Street, 2006: An unstructured-grid, finite-volume, nonhydrostatic, parallel coastal ocean simulator. Ocean Modell., 14, 139-173, https://doi.org/ 10.1016/j.ocemod.2006.03.006.

Helfrich, K. R., 2007: Decay and return of internal solitary waves with rotation. J. Phys. Fluids, 19, 026601, https://doi.org/ 10.1063/1.2472509.

_ , and W. K. Melville, 2006: Long nonlinear internal waves. Annu. Rev. Fluid Mech., 38, 395-425, https://doi.org/10.1146/ annurev.fluid.38.050304.092129.

Jackson, C., 2009: An empirical model for estimating the geographic location of nonlinear internal solitary waves. J. Atmos. Oceanic Technol., 26, 2243-2255, https://doi.org/10.1175/ 2009JTECHO638.1.

Kao, C.-C., L.-H. Lee, C.-C. Tai, and Y.-C. Wei, 2007: Extracting the ocean surface feature on non-linear internal solitary waves in MODIS satellite images. Third Int. Conf. on Intelligent Information Hiding and Multimedia Signal Processing, Kaohsiung, Taiwan, IEEE, 27-32, https://doi.org/10.1109/ IIHMSP.2007.4457485.

Lamb, K. G., and A. Warn-Varnas, 2015: Two-dimensional numerical simulation of shoaling internal solitary waves at the ASIAEX site in the South China Sea. Nonlinear Processes Geophys., 22, 289-312, https://doi.org/10.5194/npg-22-289-2015.

Li, Q., and D. M. Farmer, 2011: The generation and evolution of nonlinear internal waves in the deep basin of the South China Sea.J. Phys. Oceanogr., 41, 1345-1363, https://doi.org/10.1175/ 2011JPO4587.1.

,,-- T. F. Duda, and S. R. Ramp, 2009: Acoustical measurement of nonlinear internal waves using the inverted echo sounder. J. Atmos. Oceanic Technol., 26, 2228-2242, https:// doi.org/10.1175/2009JTECHO652.1.

_ B. Bang, X. Chen, X. Chen, and J.-H. Park, 2016: Variability of nonlinear internal waves in the South China Sea affected by the Kuroshio and mesoscale eddies. J. Geophys. Res. Oceans, 121, 2098-2118, https://doi.org/10.1002/2015JC011134.

Lien, R. C., T. Y. Tang, M. H. Chang, and E. A. D'Asaro, 2005: Energy of nonlinear internal waves in the South China 
Sea. Geophys. Res. Lett., 32, L05615, https://doi.org/10.1029/ 2004GL022012.

— , E. A. D'Asaro, F. Henyey, M.-H. Chang, T.-Y. Tang, and Y.-J. Yang, 2012: Trapped core formation within a shoaling nonlinear internal wave. J. Phys. Oceanogr., 42, 511-525, https:// doi.org/10.1175/2011JPO4578.1.

— , F. Henyey, B. Ma, and Y.-J. Yang, 2014: Large-amplitude internal solitary waves observed in the northern South China Sea: Properties and energetics. J. Phys. Oceanogr., 44, 10951115, https://doi.org/10.1175/JPO-D-13-088.1.

Liu, A. K., S. R. Ramp, Y. Zhao, and T.-Y. Tang, 2004: A case study of internal wave propagation during ASIAEX-2001. IEEE J. Oceanic Eng., 29, 1144-1156, https://doi.org/10.1109/ JOE.2004.841392.

Orr, M. H., and P. C. Mignerey, 2003: Nonlinear internal waves in the South China Sea: Observations of the conversion of depression internal waves to elevation internal wages. J. Geophys. Res., 108, 3064, https://doi.org/10.1029/2001JC001163.

Park, J.-H., and D. Farmer, 2013: Effects of Kuroshio intrusions on nonlinear internal waves in the South China Sea during winter. J. Geophys. Res. Oceans, 118, 7081-7094, https://doi.org/10.1002/ 2013JC008983.

Pickering, A., M. Alford, J. Nash, L. Rainville, M. Buijsman, D. S. Ko, and B. Lim, 2015: Structure and variability of internal tides in Luzon Strait. J. Phys. Oceanogr., 45, 1574-1594, https://doi.org/10.1175/JPO-D-14-0250.1.

Pinkel, R., M. Buijsman, and J. M. Klymak, 2012: Breaking topographic lee waves in a tidal channel in Luzon Strait. Oceanography, 25, 160-165, https://doi.org/10.5670/oceanog.2012.51.
Ramp, S. R., C. S. Chiu, H.-R. Kim, F. L. Bahr, T.-Y. Tang, Y. J. Yang, T. Duda, and A. K. Liu, 2004: Solitons in the northeastern South China Sea. Part I: Sources and propagation through deep water. IEEE J. Oceanic Eng., 29, 11571181, https://doi.org/10.1109/JOE.2004.840839.

—, Y. J. Yang, and F. L. Bahr, 2010: Characterizing the nonlinear internal wave climate in the northeastern South China Sea. Nonlinear Processes Geophys., 17, 481-498, https://doi.org/ 10.5194/npg-17-481-2010.

Shaw, P.-T., D. S. Ko, and S.-Y. Chao, 2009: Internal solitary waves induced by flow over a ridge: With applications to the northern South China Sea. J. Geophys. Res., 114, C02019, https://doi.org/ 10.1029/2008JC005007.

Vlasenko, V., and K. Hutter, 2002: Numerical experiments on the breaking of internal solitary waves over a slope-shelf topography. J. Phys. Oceanogr., 32, 1779-1793, https://doi.org/ 10.1175/1520-0485(2002)032<1779:NEOTBO > 2.0.CO;2.

_ , and N. Stashchuk, 2007: Three-dimensional shoaling of largeamplitude internal waves. J. Geophys. Res., 112, C11018, https://doi.org/10.1029/2007JC004107.

_ C. Guo, and N. Stashchuk, 2012: On the mechanism of A-type and B-type internal solitary wave generation in the northern South China Sea. Deep-Sea Res. I, 69, 100-112, https://doi.org/ 10.1016/j.dsr.2012.07.004.

Zhang, Z., O. B. Fringer, and S. R. Ramp, 2011: Threedimensional, nonhydrostatic numerical simulation of nonlinear internal wave generation and propagation in the South China Sea. J. Geophys. Res., 116, C05022, https://doi.org/ 10.1029/2010JA016287. 